\title{
CNS Delivery Via Adsorptive Transcytosis
}

\author{
Françoise Hervé, ${ }^{1,4}$ Nicolae Ghinea, ${ }^{2}$ and Jean-Michel Scherrmann ${ }^{3}$
}

Received 12 March 2008; accepted 30 June 2008; published online 26 August 2008

\begin{abstract}
Adsorptive-mediated transcytosis (AMT) provides a means for brain delivery of medicines across the blood-brain barrier (BBB). The BBB is readily equipped for the AMT process: it provides both the potential for binding and uptake of cationic molecules to the luminal surface of endothelial cells, and then for exocytosis at the abluminal surface. The transcytotic pathways present at the BBB and its morphological and enzymatic properties provide the means for movement of the molecules through the endothelial cytoplasm. AMT-based drug delivery to the brain was performed using cationic proteins and cell-penetrating peptides (CPPs). Protein cationization using either synthetic or natural polyamines is discussed and some examples of diamine/polyamine modified proteins that cross BBB are described. Two main families of CPPs belonging to the Tat-derived peptides and Syn-B vectors have been extensively used in CPP vector-mediated strategies allowing delivery of a large variety of small molecules as well as proteins across cell membranes in vitro and the BBB in vivo. CPP strategy suffers from several limitations such as toxicity and immunogenicity-like the cationization strategy — as well as the instability of peptide vectors in biological media. The review concludes by stressing the need to improve the understanding of AMT mechanisms at BBB and the effectiveness of cationized proteins and CPP-vectorized proteins as neurotherapeutics.
\end{abstract}

KEY WORDS: adsorptive-mediated transcytosis; blood-brain barrier; cationic proteins; cell-penetrating peptides.

\section{INTRODUCTION}

In the past decade, many potential protein-based large molecule drugs and non-viral gene medicines have successfully been developed for therapeutic and/or diagnostic applications. In contrast to small drugs, these large molecules have often seen a limited pharmaceutical development or use as clinically-viable drugs. This is due to their low permeability to the plasma membrane resulting in poor cellular access. This limited access largely prohibits them from reaching appropriate sites (i.e. interior of cells and tissues) and from crossing epithelial and endothelial barriers. An extreme example of this latter difficulty is the delivery of large and/ or hydrophilic molecules to the brain.

In spite of its dense capillary network, the brain (400 miles of capillaries with a surface area of $12 \mathrm{~m}^{2}$ in the human brain) (1) is probably one of the least accessible organs to circulating compounds. The dichotomy is that permeability of the brain capillary endothelium forming the

${ }^{1}$ UFR Biomédicale, Université Paris Descartes, CNRS, UPR2228, 45 rue des Saints-Pères, 75270 Paris, France.

${ }^{2}$ Faculté de Médecine, Université Paris 12, INSERM, U841-EQ07, 8 rue du Général Sarrail, 94010 Créteil, France.

${ }^{3}$ INSERM, U705, CNRS, UMR7157, Hôpital Fernand Widal, Université Paris Descartes, Université Paris Diderot, 200 rue du Faubourg Saint-Denis, 75475 Paris, France.

${ }^{4}$ To whom correspondence should be addressed. (e-mail: francoise. herve@univ-paris5.fr) blood-brain-barrier (BBB) is about two orders of magnitude lower than that of endothelia in peripheral organs (2). The $\mathrm{BBB}$ is a nonfenestrated endothelium with narrow tight junctions between the endothelial cells (EC) which prevent the passage from blood to brain interstitium of water-soluble compounds via aqueous paracellular pathways (3). Circulating molecules may, therefore, pass from blood to brain only by one of two transcellular mechanisms: passive diffusion or catalyzed transport. As a general rule, the transcellular diffusion of a substance across the BBB depends on its lipid solubility, molecular mass and charge. Peptides and proteins are generally excluded from passive transport because of their hydrophilicity and/or molecular mass.

Biologics, such as those mentioned above, can be delivered to the brain via vesicular transport across the BBB known as transcytosis. This type of transport describes the vectorial movement of molecules within endocytic vesicles and across the cerebral EC, from the luminal cell side to the abluminal side where exocytosis occurs. The brain capillary ECs contain two kinds of vesicles that are open to the luminal blood capillary space: the caveolae, also called plasmalemmal vesicles, and the clathrin-coated pits/vesicles (Fig. 1). Soluble plasma molecules can be randomly taken up by caveolae with a bulk of blood plasma, and then be transported across cerebral ECs. This transport process, known as bulk-phase or fluid-phase transcytosis (FMT), is independent of any interaction between the transported molecules and the caveolar vesicle membrane (4). While FMT represents the main 
transport process for the transendothelial delivery of proteins from blood to underlying tissues in the periphery (4), this process occurs to a very limited degree in a healthy BBB, because of the rare occurrence of caveolae in the brain capillaries (2). Nevertheless, tiny amounts of some proteins can be transported in this way across the BBB (Table I). In contrast, the brain capillary ECs are characterized by a high density of clathrin-coated pits/vesicles (5). Because the clathrin-coated pits that open at the luminal brain endothelial surface are negatively charged (Fig. 1), they will repel anionic molecules. Thus, only a very small portion of the plasma proteins can be transcytosed randomly within the fluid phase of transport clathrin-coated vesicles.

Molecules can be transcytosed by adsorption to the clathrin-coated or caveolar vesicle membrane. In contrast to FMT, adsorptive transcytosis requires the interaction of a ligand with moieties expressed at the luminal surface of cerebral EC. It can be divided into specific (receptor-mediated transcytosis; RMT) and nonspecific (adsorptive-mediated transcytosis; AMT) processes. The former is triggered by a specific interaction with receptors expressed on cerebral EC. A limited set of proteins and peptides are transported across the BBB via RMT (Table I), the three best-studied ligands being insulin, iron-transferrin and LDL-cholesterol (2). Both insulin and transferrin receptors are enriched in cerebral ECs, but relatively tiny amounts of insulin and transferrin are delivered into the brain mass via RMT. These small quantities are often sufficient to maintain BBB and brain homeostasis through hormonal effects (i.e. insulin) or by supplying essential molecules such as iron and cholesterol (2). Molecules that penetrate the brain via AMT include, but are not limited to, various cationic proteins (Table I).

Many brain drug delivery strategies have focused on RMT and AMT, although the RMT pathway has been used more actively because specificity is preferable, especially for

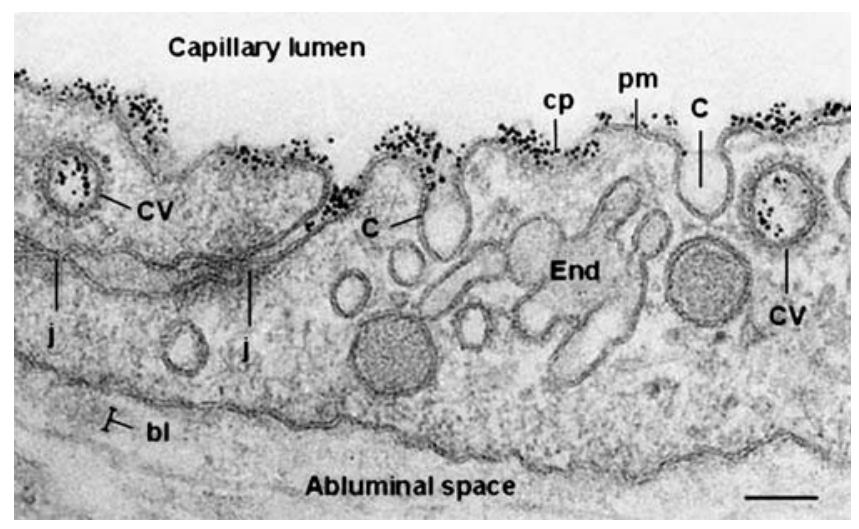

Fig. 1. The luminal surface of endothelial cells of an adult mouse brain capillary labeled with cationized bovine serum albumin-gold conjugate (gold particle size: $5 \mathrm{~nm}$ ). After $3 \mathrm{~min}$ of brain perfusion in situ, the gold particles, distributed in small clusters on the luminal plasma membrane $(\mathrm{pm})$, also mark the negative charges associated with the membrane of coated pits $(c p)$ open to the luminal front of endothelial cells, and coated vesicles $(c v)$. In contrast, the luminal caveolae (c) are not significantly labeled by the cationic marker. Furthermore, the gold particles do not penetrate beyond the tight junctions (j). Bar: $100 \mathrm{~nm}$. Other abbreviations: bl, basal lamina; End, endosomal compartment (N. Ghinea, unpublished results) toxic agent delivery (e.g. anti-cancer drugs). In this view, the brain endothelial transferrin and insulin receptor transport systems have been given particular attention $(1,6)$. More specifically, the anti-transferrin receptor antibody, OX26, which is transcytosed into the brain mass, has been used to shuttle biologics chemically attached to the antibody or encapsulated into antibody-functionalized carriers (immunoliposomes) across the BBB (7). Because the amounts of OX26 antibody delivered to the brain are extremely low ( $<1 \%$ of the dose injected), and as there is no definitive evidence for quantitative transcytosis of the receptor along with the cargo, this approach is being combined with other molecules that transiently open tight junctions to deliver macromolecule drugs (8). Therefore and because of the increasing need to solve the BBB drug delivery problem, increasing attention has been paid to the potential of AMT in protein-based-drug discovery.

\section{ADSORPTIVE-MEDIATED TRANSCYTOSIS AND ITS PROPERTIES}

\section{Origin of the Concept}

The concept of AMT through the BBB originated with the observation that polycationic proteins such as protamine could not only bind to the endothelial cell surface but could also penetrate the BBB (9). Moreover, mixing protamine, poly-L-lysine or other cationic molecules with proteins (e.g. albumin and horseradish peroxidase) greatly increased the permeability of these proteins across cerebral microvessels $(9,10)$. This could probably be due to their binding affinity for polycations. In a similar manner, cationized proteins can be transported through the BBB (1). These findings were explained by adsorptive-mediated endocytosis triggered by electrostatic interactions between the positively charged moieties of the proteins and negatively charged membrane surface regions on the brain ECs (11). As a consequence, the cationic net charge of a peptide/protein has gradually become recognized as an important determinant in the brain capillary uptake of these molecules.

\section{AMT and the BBB}

The BBB is readily equipped for the AMT process: it provides both the potential for binding of cationic molecules to the luminal surface of endothelial cells, and then for exocytosis at the abluminal surface; the transcytotic pathways present at the $\mathrm{BBB}$ and its morphological and enzymatic properties, as well as the high content of mitochondria in cerebral ECs provide the means for movement of the molecules through the endothelial cytoplasm.

\section{Glycocalyx and Negative Charges at the BBB Surface}

At systemic physiological $\mathrm{pH}$, the luminal surface of cerebral ECs presents an overall negative charge. Early ultrastructural studies (12) established that sialo-glycoconjugates and heparan sulfate proteoglycans, which constitute the glycocalyx, provided the negative charge barrier. Moreover, not only could anionic sites be described on the luminal surface of cerebral ECs, but also on the abluminal surface. 


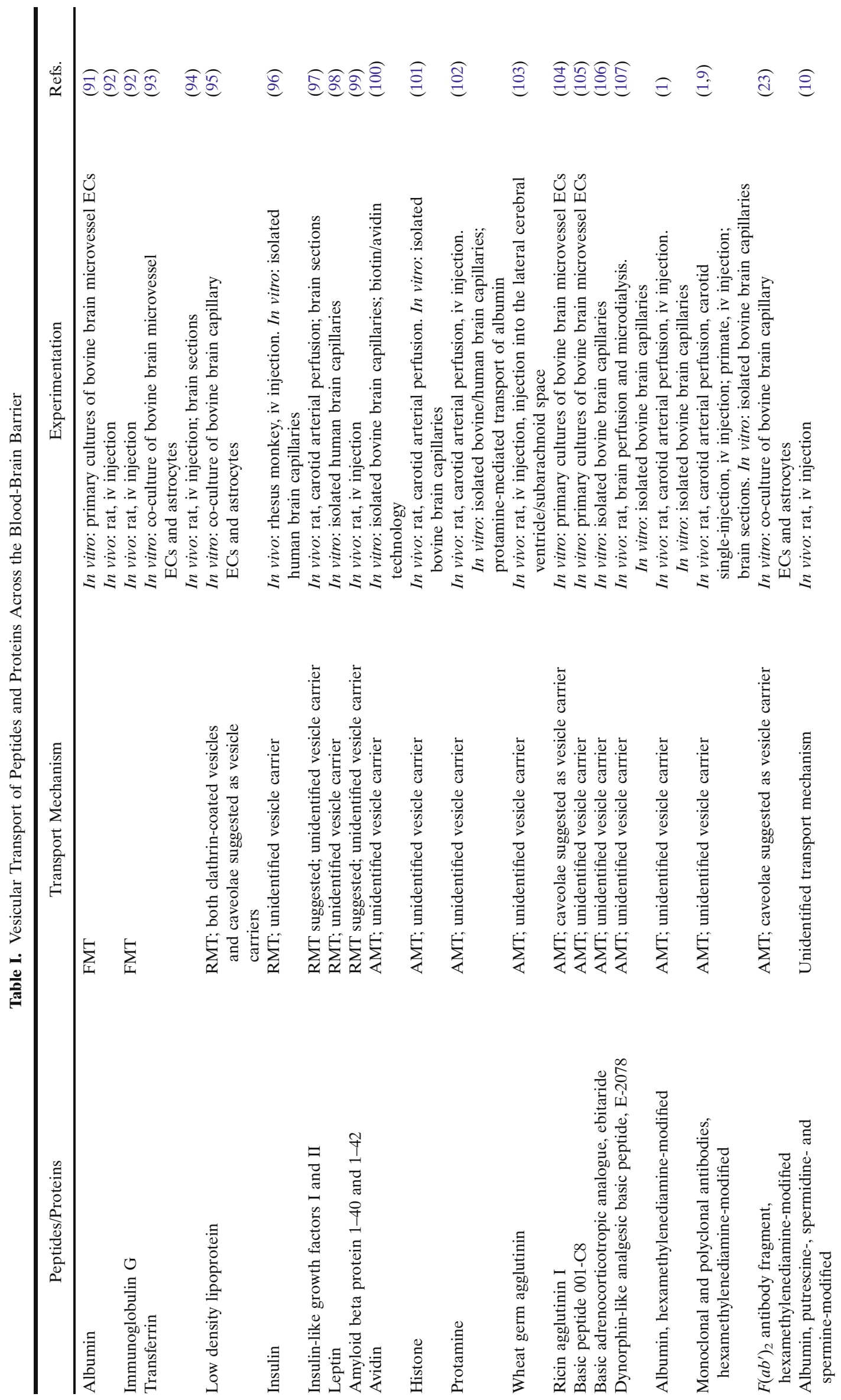




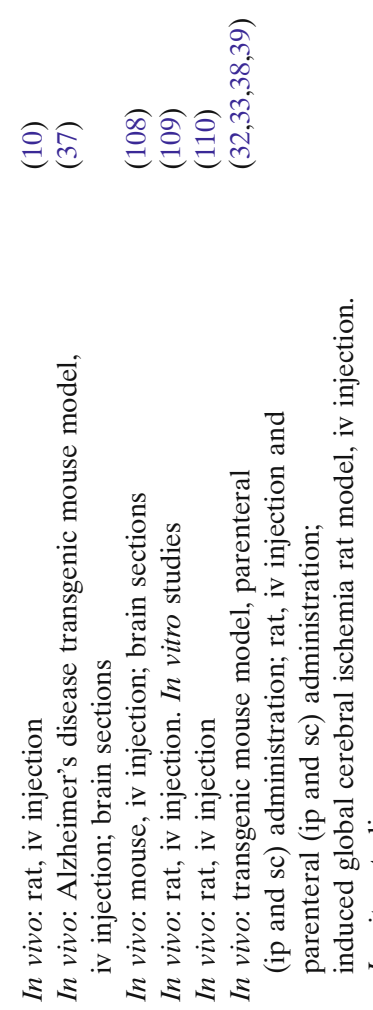

Combinations of enzymatic treatments and cationic tracers, however, demonstrated distinct differences between these two surfaces (12). A more intense labeling of the luminal surface with cationic colloidal gold was reached, indicating a polar distribution of anionic components of the plasma membrane (Fig. 2). The anionic sites of the luminal front mainly represent carboxyl groups of sialic acid-containing glycoproteins which can be digested with neuraminidase, and to a lesser degree, sulfate groups of heparan sulfate proteoglycans. The abluminal anionic sites are neuraminidaseresistant, and are in fact digested by an heparinase that cleaves heparan sulfates. These mainly consist of mixed proteoglycans. Heparan sulfates are the main glycosaminoglycans (GAGs) of the endothelial cell glycocalyx. The dominating heparan sulfate proteoglycans (HSPGs) at the endothelial cell surface are the syndecans and glypicans (for further details, see Fig. 3). It has to be stressed that HSPGs are suspected of playing a critical role in cellular internalization of basic peptides, growth-promoting polyamines and polycation-nucleic acid complexes, with possible applications associated with protein delivery and gene transfer into cells (13). The basement membrane contiguous to the basolateral side of the cerebral ECs is also a negatively charged barrier due to its chondroitin and heparan sulfate-rich GAG components. Perlecan, the least common among HSPGs, is located within the basement membrane. All three of these successive electrostatic barriers create an environment selective to positively charged substances (Fig. 2). The carbohydraterich layer which extends into the capillary lumen provides anionic sites (i.e. carboxyl groups of sialic acid residues) for the binding of cationic substances to the luminal side of cerebral ECs. The anionic properties of both the abluminal cell side and the basement membrane (i.e. the sulfate groups of GAG components) may facilitate the externalization of cationic substances from the lumen of the transport vesicles, and their transfer to the brain interstitium.

\section{Morphological, Enzymatic and Energy Properties}

The wall thickness of brain capillaries is roughly $40 \%$ lower relative to peripheral capillaries (14). It has been suggested that this difference may be a modulation of the restrictive permeability of the $\mathrm{BBB}$, allowing substances a shortened transport time to cross through the membrane and cytoplasm of the EC and enter the brain parenchyma.

Transcytosis of molecules at the BBB is an energyrequiring/ATP-dependent transport process, both for the endocytosis of the transported molecule at the luminal side of the EC and for its transport across the EC as well as for its exocytosis at the basolateral side. The density of mitochondria in cerebral EC is roughly five times greater than in peripheral endothelia (15), increasing the energy potential of the BBB as well. This enhanced cerebral capillary work capacity may be related to energy-dependent transcapillary vesicular transport. Exocytosis of the molecules from the vesicular compartment requires the fusion of the vesicle membrane with the plasma membrane, a process presumably regulated by protein phosphorylation and dephosphorylation (16). With regard to this, the brain capillary endothelium has a high activity of both protein kinases and phosphatases involved in protein phosphorylation (17). 


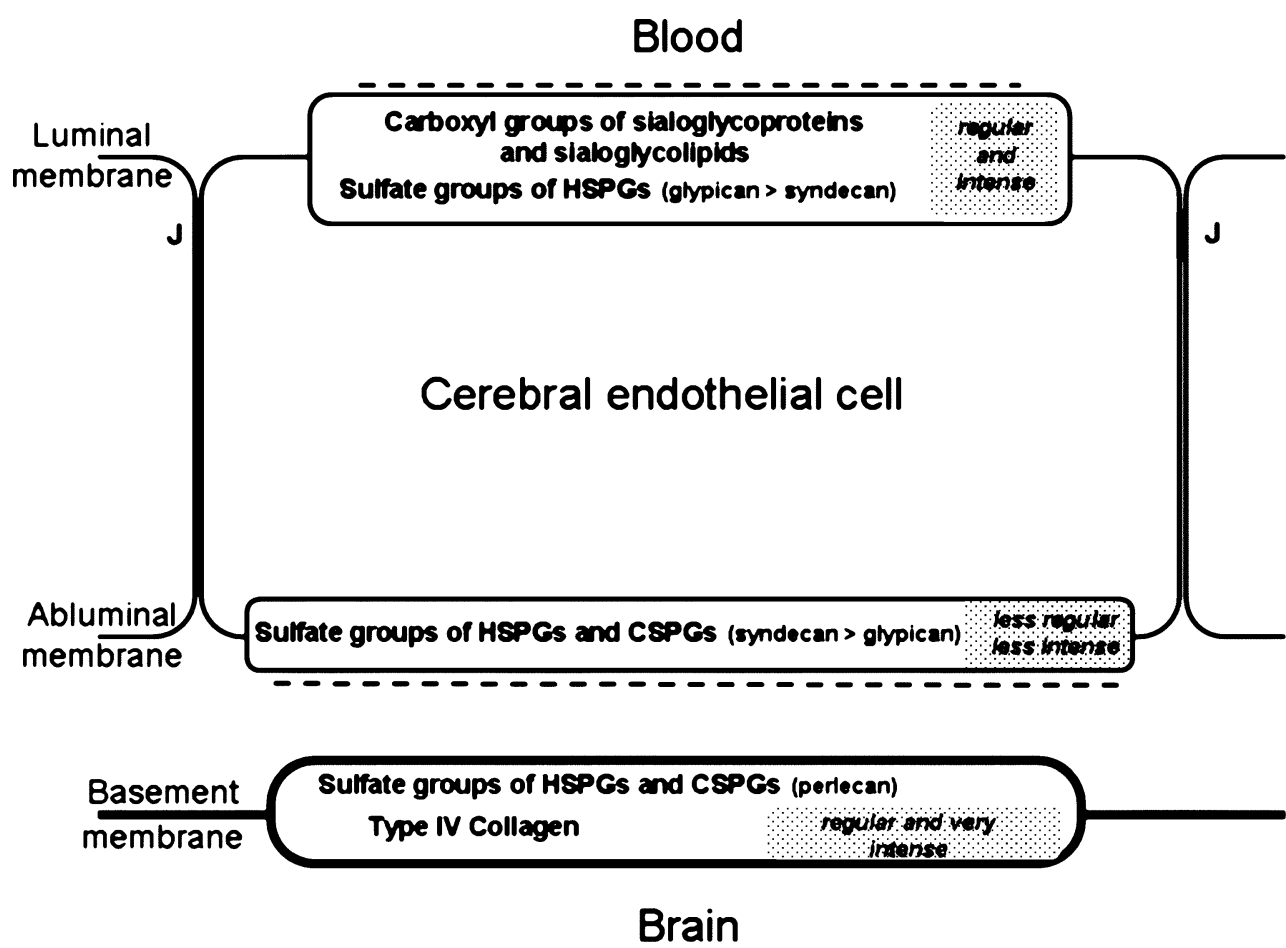

Fig. 2. Endothelial cell surface and basement membrane components bearing anionic charges at the blood-brain barrier, which allow the adsorptive-mediated transcytosis of cationic substances. Abbreviations: $H S P G s$, heparan sulfate proteoglycans; CSPGs, chondroitin sulfate proteoglycans; $J$, tight junction

\section{Transcytotic Pathways Across the BBB}

This stage of transcytosis at the BBB starts with uptake either through clathrin-coated pits or caveolae. The beststudied of the two is that involving clathrin, which forms coated membrane invaginated structures or pits on the plasma membrane. As mentioned above, the brain capillary endothelium is particularly enriched in clathrin-coated pits/ vesicles, compared to peripheral endothelia (5). Caveolae are flask-shaped, non-coated membrane invaginations, which are characterized by their association with caveolin and their enrichment in cholesterol and glycosphingolipids. Molecules found within caveolae, such as glycosyl phosphatidyl inositol (GPI)-anchored proteins, are not present in the coated pits. Conversely, typical markers for clathrin-mediated endocytosis, such as the transferrin-receptor, are not present in caveolae. Clathrin-coated pits and caveolae are found at both the luminal and abluminal plasma membranes of the cerebral ECs. However, the clathrin-coated pits are much more abundant at the luminal than at the abluminal side (5), indicating that transcytosis mediated by the clathrin pathway will mainly function unidirectionally, i.e. from blood to brain (Fig. 4). This also applies to transcytosis mediated by caveolae, but again, the brain ECs have a low frequency of plasmalemmal vesicles $\left(<100 / \mu \mathrm{m}^{3}\right)(2)$. In both cases, the clathrin-coated pits and caveolae provide the potential to mediate endocytosis and to function in the transcellular movement of selected molecules $(18,19)$.

Clathrin-coated pits recruit cell-surface receptors and then, through a series of highly regulated steps, pinch off to form clathrin-coated vesicles. While some receptors may be predominantly localized in the coated pits, even in the absence of ligand binding, others such as the transferrin receptor, accumulate selectively in coated pits only upon ligand binding (20). As demonstrated in peripheral blood vessels, caveolae may contain an abundance of membrane receptors and transporters, as well as signaling molecules, which suggests their possible involvement in various important cellular processes, in addition to their role in the endocytosis/transcytosis of specific molecules (19).

The coated pits and the caveolae mediate the transcytosis of different sets of molecules across endothelial barriers. As illustrated for the BBB in Fig. 4, the caveolae may bud to form free, apparently intact (no caveolin uncoating) vesicles for direct transendothelial transport to underlying tissue cells (19). At the same time, once the clathrin-coated vesicles have formed, they lose their clathrin coat and the uncoated vesicles may fuse with a transcytotic endosome (21) (Fig. 4). From there, the internalized receptors and ligands may cross the cell and be delivered to the opposite membrane (transcytosis).

Alternatively, the molecules internalized in clathrincoated vesicles or caveolae can traffic through the brain ECs to allow for accumulation in lysosomes for degradation. As demonstrated in peripheral microsvascular ECs, the degradative endocytic pathways mediated by the caveolae and by the clathrin-coated vesicles differ in some early aspects (19). However, with time, ligands internalized by caveolae finally converge with ligands of the clathrin-coated vesicle pathway within later-stage endosomes and lysosomes.

The vesicular route used for the transcytosis of cationic substances through the BBB is not well known. What is known is that AMT may not involve specific plasma membrane receptors and that endocytosis is initiated through 


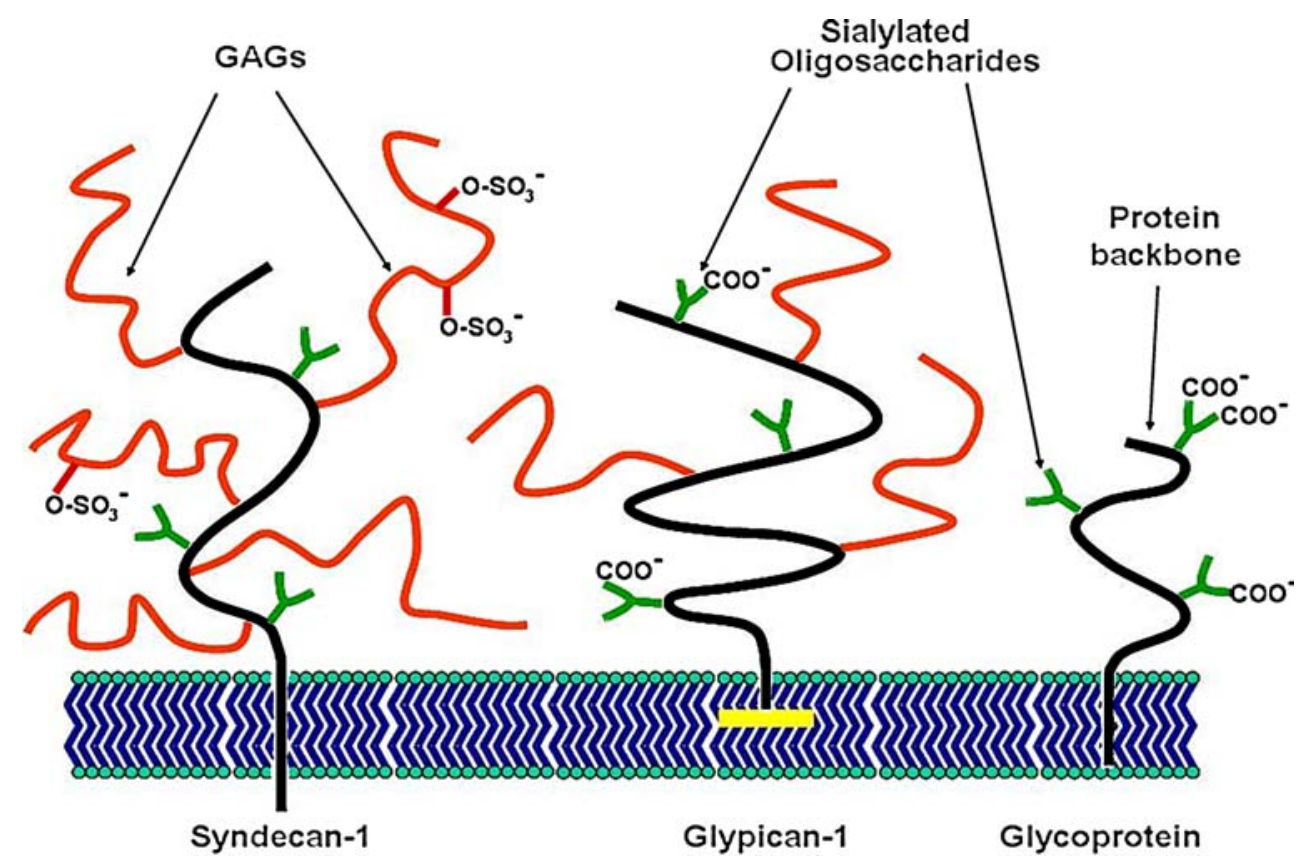

Fig. 3. Schematic overview of major cell-surface glycan-containing components. The syndecans and glypicans form the two most common groups of heparan sulfate proteoglycans on the endothelial surface. The backbone structure of HS consists of $N$-acetylglucosamine-glucuronic acid disaccharides $(n=10-50)$, which are modified by the addition of sulfate groups at various positions. The syndecan family (four members) consists of transmembrane HSPGs which all have highly variable extracellular domains, but have homologous transmembrane and cytoplasmic domains. The syndecans exhibit cell-type specific distribution with vascular endothelial cells (ECs) expressing syndecan-1, -2, and -4 and predominant targeting to abluminal surfaces. They are the only HSPGs that penetrate the cytoplasm, thus allowing for interaction with the cytoskeleton (syndecan-1) or focal adhesion molecules (syndecan-4). Syndecan-1 has both HS and chondroitin sulfate (CS) glycosaminoglycans (GAGs). The glypicans (six members) possess structural similarity, and typically differ in the number of GAG attachment sites in the extracellular region. They are linked to the cell surface through a $\mathrm{COOH}$-terminal GPI anchor (yellow bar in the figure). In contrast to the syndecans, glypicans contain HS only. The glypicans are selectively expressed on different cell types with only glypican-1 present on vascular ECs. These HSPGs are mainly targeted to luminal surfaces. Perlecan (not represented) is the least common HSPG and consists of only one variant with a total of five GAG linkages. Sialylated glycoproteins contain only oligosaccharide chains with alpha- and beta-galactosyl residues, and alpha-mannosyl/glucosyl residues linked to $N$-acetylglucosamine. The oligosaccharide chains are terminated by sialic acid residues in the alpha 2-3 and/or 2-6 linkages. For a review on HSPG, see (13)

charge-charge interaction between polycationic substances and negative charges on the endothelial surface. The clathrincoated pits along the luminal surface of ECs are negatively charged (Fig. 1), and thus capable of binding positively charged substances. Moreover, glycoprotein receptors that concentrate in coated pits, such as the transferrin receptor (22), contain multiple sialic acid residues, and may contribute to the negative charge of the clathrin-coated microdomains.

A few studies have demonstrated that caveolae are involved in AMT, as seen in the transcytosis of cationized $F\left(a b^{\prime}\right)_{2}$ antibody fragments across an in vitro BBB model (23). That being said, it must be pointed out that endocytosis of cationized $F\left(a b^{\prime}\right)_{2}$ and $F a b$ fragments can occur in cells devoid of caveolae (24-26). Furthermore, the intracellular delivery of Syn-B peptides, a family of cell-penetrating peptides that exhibit charge-mediated BBB selectivity, appears to occur via a caveolae-independent pathway (27). In the same vein, two endocytic pathways have been described for natural polyamines in various cultured cells: one would be through receptor-mediated endocytosis via coated pits (28), and the other via caveolae after binding to glypican-1 at the exofacial side of the plasma membrane (29).

\section{Transport Properties of AMT}

Both in vitro and in vivo studies provide evidence that brain uptake via AMT and RMT are time- and concentrationdependent processes which require energy (1). The kinetic of brain uptake via AMT or RMT across the BBB is as slow as that which is characteristic of endocytosis: the transport takes minutes to occur and is much longer than the carrier-mediated transport of nutrients (e.g. glucose) (30). Although AMT may not involve binding specifically to plasma membrane receptors, both AMT and RMT are saturable transport processes. The main difference between AMT and RMT lies in that the former becomes saturated at higher concentrations than the latter. Indeed, the maximum binding capacities $\left(B_{\max }\right)$ for AMT are of the order of several nanomoles per milligram of membrane protein (1), values that are several thousand times greater than those for RMT $\left(B_{\max }<1 \mathrm{pmol} / \mathrm{mg}\right.$ of membrane protein). However, AMT is also characterized by micromolar half-saturation constants, as opposed to RMT which has $K_{\mathrm{D}}$ values in the low nanomolar range. Since the occupancy of binding sites depends on both affinity and capacity, the affinitycapacity product for AMT is relatively similar to that for RMT. 


\section{Luminal front}

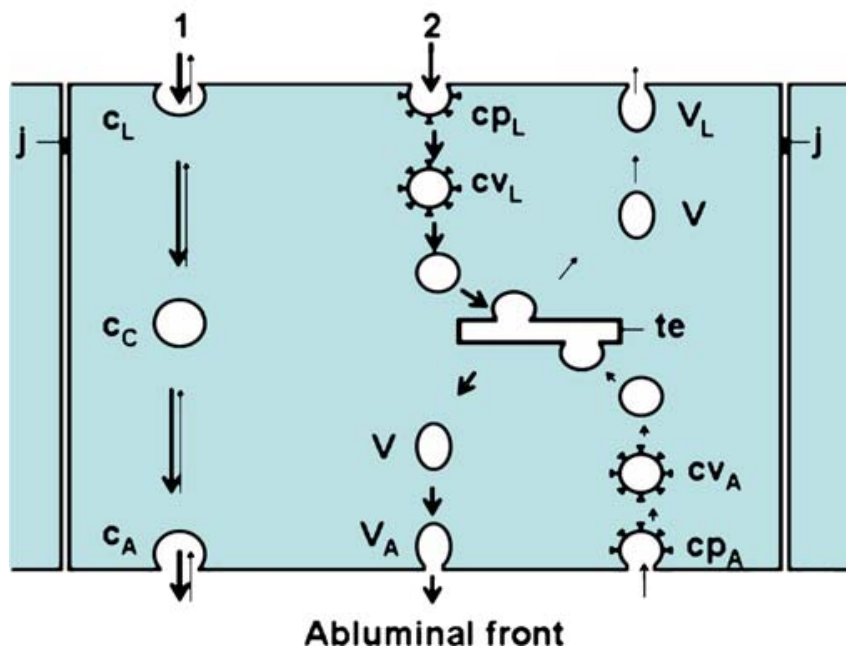

Fig. 4. Schematic representation of the vesicular transendothelial pathways in brain capillaries involving the caveolar (1) and the clathrin-coated pit/vesicle (2) systems. The bold arrows indicate principal routes of transport from blood to brain tissue; the thin arrows indicate limited transport from brain towards blood plasma. Abbreviations: $c_{A}$, caveolae open to the abluminal front; $c_{C}$, cytoplasmic caveolae; $c_{L}$, caveolae open to the luminal surface of the cerebral endothelial cells; $c p_{A}$, clathrin-coated pit open to the abluminal front; $c p_{L}$, clathrin-coated pit open to the luminal front; $c v_{A}$, clathrin-coated vesicle associated with the abluminal endothelial surface; $c v_{L}$, clathrin-coated vesicle associated with the luminal endothelial surface; $V$, smooth vesicle; $V_{A}$, smooth vesicle open to the abluminal front; $V_{L}$, smooth vesicle open to the luminal front; $j$, tight junction; te, transcytotic endosome

\section{AMT-BASED DRUG DELIVERY STRATEGIES}

The physiologically-based strategies developed to increase BBB permeability to hydrophilic and/or large molecules take advantage of the various transport mechanisms identified at the BBB. RMT, and more importantly in the present context, AMT, are good candidates for the transport of macromolecules. In this section, we will specifically discuss the cationization and cell-penetrating peptides, and also the limitations and pitfalls involved in the investigation and development of these strategies that use AMT.

\section{Protein Cationization}

As seen earlier, AMT is a transport process that applies to cationic proteins (11). Due to the abundance of polyanions that surround the $\mathrm{BBB}$, cationization of proteins is a reasonable choice to endow them with the ability to cross the BBB via AMT.

\section{Cationization Methods}

The simplest way to chemically cationize a protein is the amidation of its carboxylic acid groups (i.e. carboxy-terminal group, as well as glutamic (Glu) and aspartic acid (Asp) side chain groups) with positively charged amines. This reaction is usually accomplished by the carbodiimide-mediated amidation of these groups (Fig. 5). The advantage of this type of modification is the direct delivery of the protein itself without depending on a cationic import carrier. Various diamines and polyamines, either synthetic or natural, have been attached to proteins to form amide linkages. Examples of these are given in Table II. The most widely used polyamine molecule in the case of BBB transfer is probably the synthetic hexamethylenediamine or HMD $(1,9)$. Yet, there are naturally occurring polyamines that have also been used, such as putrescine (PUT), spermidine (SPD) and spermine (SPM) (10). The interesting aspect to these three polyamines is their increasing net positive charge valency. Furthermore, they are ubiquitously present in all mammalian cells and involved in pathways for posttranslational modifications of proteins (31). It has been suggested that the modification of these polyamine-conjugated proteins may facilitate their transport across cell membranes (10).

The extent to which a given protein can be cationized primarily depends on the amino-acid composition and conformation of the protein itself, i.e. the greater the number of accessible carboxyl groups, the higher the degree of cationization. It also depends on the molar excess of polyamine and carbodiimide relative to the protein carboxyl groups $(9,26)$. The polyamine excess prevents protein polymerization via intermolecular cross-linking and ensures that only one terminal amino group of the polyamine couples to one carboxyl group on the protein. Cationization is a $\mathrm{pH}$ dependent reaction, and increases as the $\mathrm{pH}$ decreases $(9,26)$. Protein cationization can significantly raise the cationic net charge, which can be identified by isoelectric focusing. Procedures involving the use of radiolabeled polyamines can be used to quantitatively determine the extent of cationization of a protein if necessary $(25,26)$.

\section{Sidetracks: Biological Activity and Radiolabeling}

Cationization can compromise the protein activity either by direct derivatization of crucial Asp or Glu residues in the following locations: sites of antibodies which bind antigens, sites of enzymes which bind substrates, and in the case of albumin, sites which bind therapeutic ligands. Cationization of peptide hormones or growth factors can also alter their binding to their specific receptors. Alteration can also take place through conformational changes. For some proteins, the biological potency may be completely destroyed after cationization (9), whereas it may only be altered to a certain extent for others $(26,32,33)$. A strategy for retaining the activity of selected proteins may be protein site protection during the reaction with, for example, the antigen or substrate. The linkage of the cationizing groups to parts of the protein which are far from the binding or active domain (e.g. glycan chains of immunoglobulins) may also be a suitable strategy (1).

The degree of cationization of the protein may be critical for its pharmacokinetic fate. Mildly cationized albumins with isoelectric point $(\mathrm{p} I)$ values ranging between 7.2 and 9 have been shown to display more favorable pharmacokinetic properties than heavily cationized albumins with $\mathrm{p} I$ values of more than 9, both in terms of plasma half-life and selectivity to brain tissue, as compared to other organs (1). This should be taken into account when considering the use of cationized albumin as a possible brain drug transport vector in vivo. Undesirable effects on the pharmacokinetic properties of cationized proteins may not necessarily be linked to cationization in itself, but to the radiolabeling 


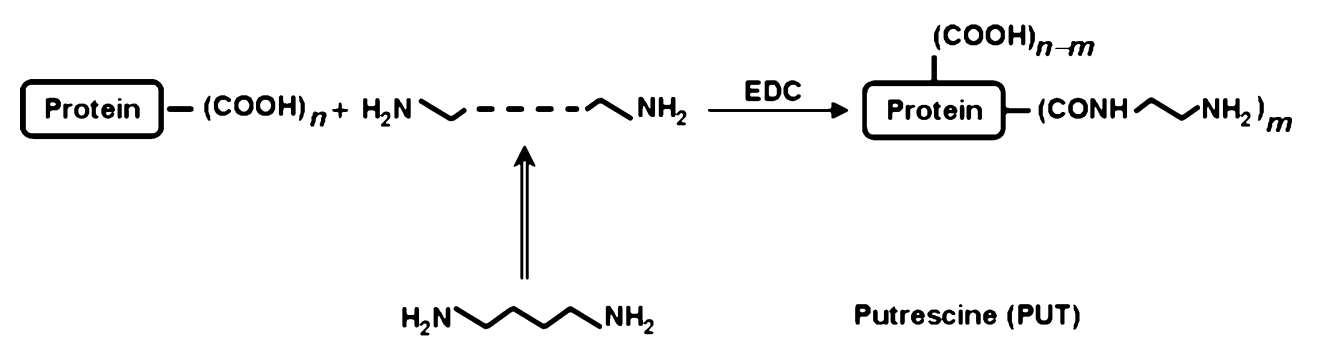

$\mathrm{H}_{2} \mathrm{~N} \mathrm{NH}_{2}$

Hexamethylenediamine (HMD)

$\mathrm{H}_{2} \mathrm{NH}$

Spermidine (SPD)

\section{Spermine(SPM)}

Fig. 5. Schematic of the procedure for the chemical modification of a protein by amidation of its carboxylic acid groups (carboxy-terminal group, Glu and Asp side chain groups) with a diamine or polyamine. The carboxyl groups on the protein are activated using a carboxyl activator like $N$-ethyl- $N^{\prime}-3$-(dimethylaminopropyl)carbodiimide (EDC). The chemical structures of the diamines or polyamines that can be used to covalently modify proteins for their delivery across the blood-brain barrier are shown. Examples of these modified proteins are given in Table II

Table II. Peptides and Proteins Covalently Modified with Diamines/Polyamines, and their Potential Use as Neuropharmaceuticals

\begin{tabular}{|c|c|c|c|}
\hline Diamine/polyamine & Protein/peptide & Potential applications & Refs. \\
\hline \multirow{9}{*}{$\begin{array}{l}\text { Hexamethylenediamine } \\
\text { (HMD) }\end{array}$} & \multirow[t]{4}{*}{ Albumin } & Cationized albumin as drug transport carrier & (1) \\
\hline & & $\begin{array}{l}\text { Cationized albumin-avidin conjugate: delivery } \\
\text { of biotinylated therapeutics }\end{array}$ & (6) \\
\hline & & Albumin/beta-endorphin chimeric peptide & $(111)$ \\
\hline & & $\begin{array}{l}\text { Cationized albumin coupled to liposomes, } \\
\text { as drug carriers }\end{array}$ & (112) \\
\hline & Anti-betaA4 protein antibodies & In vivo diagnosis of Alzheimer's disease & (9) \\
\hline & $\begin{array}{l}\text { Anti-epidermal growth factor (EGF) } \\
\text { receptor and anti-tenascin-antibodies }\end{array}$ & $\begin{array}{l}\text { Radio-immunoimaging and radio-immunotherapy } \\
\text { of malignant brain tumors }\end{array}$ & (9) \\
\hline & Anti-ras oncogene antibodies & Intracellular immunization; therapeutics of cancer & (9) \\
\hline & Anti-rev protein antibodies & $\begin{array}{l}\text { Intracellular immunization; therapeutics of HIV-1 } \\
\text { infection }\end{array}$ & (9) \\
\hline & Anti-tetanus toxin antibodies & Anti-tetanus therapy & (23) \\
\hline \multirow[t]{8}{*}{ Putrescine (PUT) } & Anti-amyloid beta peptide antibodies & $\begin{array}{l}\text { Immunotherapy of Alzheimer's disease; imaging } \\
\text { of amyloid plaques }\end{array}$ & $(37,113)$ \\
\hline & Amyloid beta protein $1-40$ & Diagnosis of Alzheimer's disease & $(108)$ \\
\hline & Beta-sheet breaker peptide & $\begin{array}{l}\text { Inhibition of amyloidogenesis In vivo; therapy } \\
\text { for Alzheimer's disease }\end{array}$ & (109) \\
\hline & Nerve growth factor & Treatment of neurological diseases & $(110)$ \\
\hline & Superoxide dismutase & Treatment of ischemic neuronal degeneration & $(33)$ \\
\hline & \multirow[t]{2}{*}{ Catalase } & $\begin{array}{l}\text { Treatment of free radical associated neurodegenerative } \\
\text { disorders }\end{array}$ & $(32)$ \\
\hline & & Treatment of familial amyotrophic lateral sclerosis & $(32,38,39)$ \\
\hline & Anti-tetanus toxin antibodies & Anti-tetanus therapy & $(25,26)$ \\
\hline \multirow{4}{*}{$\begin{array}{l}\text { Spermidine (SPD) } \\
\text { and Spermine (SPM) }\end{array}$} & Albumin & Polyamine-modified albumin as drug transport carrier & $(10)$ \\
\hline & Nerve growth factor & Treatment of neurological diseases & (10) \\
\hline & Superoxide dismutase & Treatment of ischemic neuronal degeneration & $(10)$ \\
\hline & Anti-tetanus toxin antibodies & Anti-tetanus therapy & $(26)$ \\
\hline
\end{tabular}


method used to quantify the plasma and tissue distribution of these proteins. The in vivo brain uptake of cationized immunoglobulin $\mathrm{G}(\mathrm{IgG})$ may be severely diminished after protein iodination, due to a serum inhibition phenomenon, whereas no such inhibitory effect is observed when the same cationized $\operatorname{IgG}$ is tritiated $(1,9)$. Moreover, the same radiolabeling method applied to two different cationized antibodies can affect their pharmacokinetic behavior differently (9). This particular point is important when the cationized protein is intended for use as a radiolabeled tracer in imaging or treating brain tumors or diseases. Finally there is no rule of thumb, each protein having to be studied in and of itself. It is necessary to find both the appropriate conditions to cationize a protein without appreciable loss of potential activity, and a corresponding radiolabeling method which gives the desired pharmacokinetic profile in experimental animals (i.e. rapid plasma clearance and brain uptake).

\section{Limitations and Pitfalls}

Random Distribution. A serious limitation for the in vivo use of cationized proteins is their potentially high adsorptive property towards anionic sites of cell surfaces (e.g. HSPGs and phospholipids in the outer leaflet of the cell membrane) which are found in all living cells. This property tends to favour random tissue and organ distribution of cationized proteins, and can be a disadvantage for specific targeting of a desired organ, particularly when the protein is administered intravenously. Figure 6 illustrates the rapid and extensive distribution of cationized anti-tetanus $F\left(a b^{\prime}\right)_{2}$ as compared to native $F\left(a b^{\prime}\right)_{2}$ after intravenous administration to rats. Based upon the respective volumes of distribution calculated for both antibodies from plasma kinetic data, there is a ten-fold increase in the apparent tissue distribution of the cationized $F\left(a b^{\prime}\right)_{2}$, which may be partly explained by the adsorption of the cationized antibody to blood vessel membranes. In order to ensure that a sufficient dose reaches the desired organ (i.e. the brain in the present context), higher doses of the cationized protein must be given. However, at high doses, endothelial damage is frequently observed resulting from the widespread deposit of cationized proteins on blood vessel membranes.

Nevertheless, there is no general rule of thumb; in spite of the risk of non-specific delivery, brain-specific distribution of cationized proteins may well occur (1), as shown in Table II. Specific organ delivery of cationic proteins depends on multiple factors, including dosage and route of administration. It may also involve specific interactions between particular tissue components and the cationic element attached to the vectorized protein. In this respect, a high level of brain distribution, compared to the distribution to other organs, was clearly observed for cationic cell-penetrating peptide vectors derived from protegrin 1 (34), as described later in this article. In conclusion, transendothelial organ uptake of cationized proteins shows considerable variation in different organs and for different cationized proteins. Therefore, before restricting cationized proteins to local administration for in vivo use, or to certain in vitro applications, the efficiency of targeting these proteins to the brain must be evaluated case by case.

Toxicity. The property of cationized proteins to efficiently penetrate cells raises the question of the potential toxicity and immunogenicity of these proteins. The possible

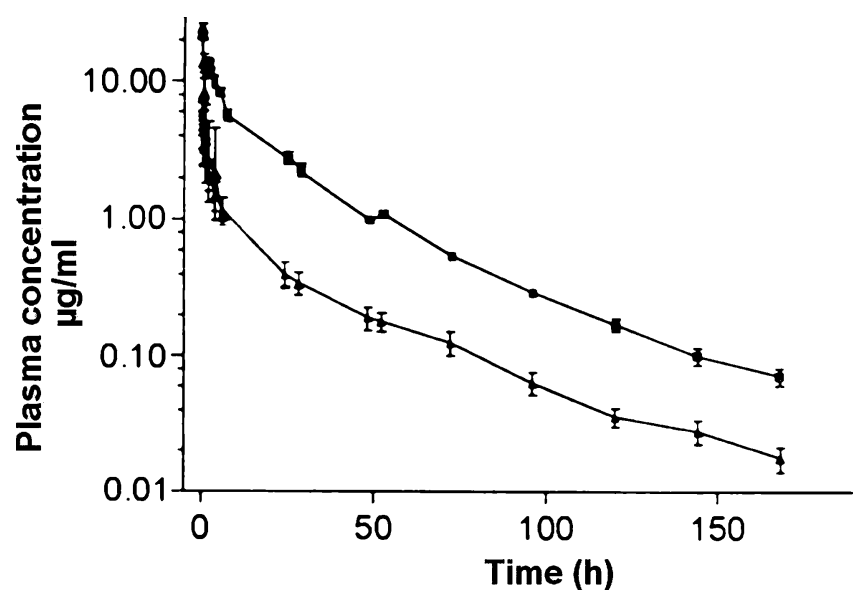

Fig. 6. Pharmacokinetics in rats of native and cationized anti-tetanus $F\left(a b^{\prime}\right)_{2}$ antibody fragments. The figure shows the plasma concentration-time curves, after intravenous bolus injection in the femoral vein of anesthetized rats, of ${ }^{125}$ I-labeled native $F\left(a b^{\prime}\right)_{2}$ (upper curve) and ${ }^{125}$ I-labeled cationized $F\left(a b^{\prime}\right)_{2}$ (lower curve). The dose of antibody injected to the rats was $700 \mathrm{mg} / \mathrm{kg}$ or $120 \mu \mathrm{Ci} / \mathrm{kg}$ for both the cationized and native $F\left(a b^{\prime}\right)_{2}$. Data are mean $\pm \mathrm{SD}(n=5$ rats for each antibody; JM Scherrmann, unpublished results)

toxic effects include a generalized increase in vascular permeability and immune complex formation with associated membrane nephropathy. A breakdown of BBB permeability and other vascular beds has been observed following intravenous injection of large amounts of cationic proteins, but has not been seen when moderate amounts of these substances were administered (1). It is known that cationic antigens and immune complexes containing cationic antibodies can deposit in glomeruli, which may result in immune complex-mediated glomerulonephritis. There are, however, examples of long-term administration of cationic proteins to humans without toxic or adverse effects $(1,35)$.

Immunogenicity. The possible immunogenicity of cationized proteins seems to principally reside in pre-existing immunogenicity to foreign proteins. Indeed cationization of proteins results in a relatively mild immune response and no measurable toxic effects when they are administered to "homologous" animals. Humanized monoclonal antibodies have been used in high doses in human subjects without eliciting significant immune responses (1). In contrast, "heterologous" cationized proteins used even at low doses have been shown to be highly immunogenic (36). In view of this, human proteins or recombinant humanized proteins should be used for cationization and subsequent applications in humans. As the conjugation of proteins to polyethylene glycol has been shown to decrease their immunogenicity, PEGylation of cationized molecules may be an alternative to minimize the immunogenic potential of these molecules.

\section{Examples of Diamine/Polyamine Modified Proteins that Cross} the $B B B$

In spite of the aforementioned drawbacks, cationization has found its place in BBB transport of proteins and peptides. Table II gives examples of these and also the potential 
applications of this transport. For all the proteins included in this table, their covalent modification with a diamine or polyamine has been shown to greatly enhance their transport across the $\mathrm{BBB}$ in vivo $(1,10)$ or in vitro $(1,9,23)$. Most of the examples given highlight future biomedical prospects rather than actual applications. Nevertheless, antibodies cationized with synthetic (i.e. HMD) or natural (i.e. PUT) diamines have been used to protect the brain against viral antigens and oncogenes in tumors, and also to image specific antigens in tumors or betaamyloid deposits in subjects with Alzheimer's disease $(1,9,37)$. The dramatic increases of $\mathrm{BBB}$ permeability to superoxide dismutase (33) and catalase $(32,38,39)$ covalently modified with PUT may enhance the therapeutic usefulness of these antioxidants in treating neurodegenerative diseases $(32,33)$. The cellular uptake of anti-tetanus $F\left(a b^{\prime}\right)_{2}$ fragments by both nonendothelial (HL60) cells (26) and rat brain endothelial (RBE4) cells in culture (F. Hervé, unpublished results), is markedly increased after antibody conjugation to the natural polyamines SPD and SPM. The ability of cationized anti-tetanus $F\left(a b^{\prime}\right)_{2}$ to cross the $\mathrm{BBB}$ has also been demonstrated (23). The cationized anti-tetanus $F\left(a b^{\prime}\right)_{2}$ retained their antigen-binding activity after endocytosis $(25,26)$ or transcytosis $(23)$. This supports the possibility of using these antibodies in the treatment of tetanus, a severe disease of the CNS.

Alternative intracellular delivery strategies of proteins assisted by cationized carrier proteins have also been described and can be of interest for future study. They use protein-protein or ligand-protein interactions that are both specific and of high affinity, and since the carrier proteins are cationized, the direct cationization of the protein to be delivered is not necessary (40). Cationized carrier proteins used as models are avidin and protein G. Merely mixing an antibody with cationized protein $\mathrm{G}$ or a biotinylated protein with cationized avidin is necessary. Nonetheless, these systems have never been used for brain delivery.

\section{Alternative Transport Mechanisms of Polyamine-Modified Proteins}

Most studies with cationized proteins have pointed to an adsorptive-mediated transport mechanism across the BBB. Nevertheless it must be stressed that some authors have suggested that the increased BBB permeability to proteins covalently modified with natural polyamines (PUT, SPD and SPM) may imply mechanisms of transport other than simple electrostatic interaction involving charge density (10). Influx and efflux carrier-mediated transport processes exist at the $\mathrm{BBB}$, some of them possibly being involved in the transport of polyamines from blood to brain. Examples of these membrane-bound transporters can be seen in the choline transporter (41), and members of the OCT/OCTN family, which transport organic cations, including carnitine and neuromediators (42). Binding of substrates to membranebound transporters is thought to induce the formation of transient narrow pores, which then allow the passage of substrate molecules. Therefore, even if polyamines could enter the cerebral ECs via the above-mentioned transporters, it is unlikely that these small molecules could be used as vectors for the transport of larger molecules, such as peptides or proteins. On the other hand, endocytosis has been shown to be an integral part of the transport of polyamines into various cultured cells $(28,29)$. The possibility that polyamines may be transported in this way at the $\mathrm{BBB}$ remains to be explored, as also does the possibility that they may undergo endocytosis when carrying macromolecules.

Other AMT-based strategies for protein delivery to the brain have been proposed, which include cationic liposomes $(43,44)$ and cell-penetrating peptides. The following section will focus on the latter.

\section{Cell-Penetrating Peptides}

Discovering that small peptides derived from proteintransduction domains have the ability to translocate the cellular membranes and gain access to the cell interior, and more importantly, allow the cellular delivery of conjugated or fused biomolecules has opened up new gateways in the field of drug discovery (45). This section will touch on cellpenetrating peptides generally speaking and their mechanisms of internalization. From there, a selection of these peptides will be described leading to their potential use for transport of small drugs and protein-based large molecule drugs. And finally, we will see the limitations and pitfalls of the CPP approach.

Table III. A Selection of Commonly Used Cell-Penetrating Peptides

\begin{tabular}{|c|c|c|c|}
\hline Cell-penetrating peptides & Sequence & Origin & Refs. \\
\hline \multicolumn{4}{|l|}{ Amphipathic sequences } \\
\hline Penetratin(43-58) or $\mathrm{pAntp}_{43-58}$ & RQIKIWFQNRRMKWKK & $\begin{array}{l}\text { Drosophila melanogaster transcription } \\
\text { factor }\end{array}$ & $(45)$ \\
\hline Amphipathic model peptide & KLALKLALKALKAALKLA & Synthetic & (114) \\
\hline Transportan & GWTLNSAGYLLKINLKALAALAKKIL & Chimeric galanin-mastoparan & (115) \\
\hline SBP & MGLGLHLLVLAAALQGAWSQPKKKRKV & $\begin{array}{l}\text { Chimeric Caiman crocodylus } \operatorname{Ig}(\mathrm{v}) \\
\text { light chain-SV40 large T antigen }\end{array}$ & $(116)$ \\
\hline FBP & GALFLGWLGAAGSTMGAWSQPKKKRKV & $\begin{array}{l}\text { Chimeric HIV-1 gp41-SV40 large T } \\
\text { antigen }\end{array}$ & $(117)$ \\
\hline \multicolumn{4}{|l|}{ Cationic sequences } \\
\hline HIV Tat peptide (48-60) & GRKKRRQRRRPPQ & Viral transcriptional regulator & (48) \\
\hline Syn-B1 & RGGRLSYSRRRFSTSTGR & Protegrin 1 & (34) \\
\hline Syn-B3 & RRLSYSRRRF & Protegrin 1 & (34) \\
\hline $\begin{array}{l}\text { Homoarginine peptides } \\
\text { ((Arg)7 and (Arg) } 9)\end{array}$ & RRRRRRR(RR) & Synthetic & $(57,118)$ \\
\hline
\end{tabular}




\section{Cell-Penetrating Peptides}

So-called CPPs originate from various families (Table III). They are heterogeneous in size (10-27 amino acid residues) and sequence, but they all possess several positive charges. Some of them share common features such as an amphipathic sequence and the ability to interact with a lipid membrane (46). The CPPs derived from natural proteins include the transcription-activating factor Tat, penetratin, and the Syn-B vectors (Table III). A number of other CPPs are the result of the engineering of various short peptides like the homoarginine vectors, the model amphipathic peptide and transportan. Transportan and other chimeric peptides, such as the sequence signal-based peptide (SBP) and the fusion sequence-based peptide (FBP), contain sequences of various functions to reach synergistic translocation efficiency (Table III).

\section{Mechanisms of Internalization}

Evidence about the exact mechanisms of internalization of CPPs is scarce, and often elusive and different from one report to another. This controversy, however, may reflect the possibility that different peptides utilize different uptake mechanisms depending on their cargo and biophysical properties, or that CPP membrane translocation is mediated by several different pathways that may occur simultaneously (47).

Based on early studies, it has commonly been accepted that the internalization of CPPs was energy-independent and did not involve endocytosis, since internalization was not inhibited by low temperatures, depletion of the cellular ATP pool, or by inhibitors of endocytosis $(45,48)$. It was also seen to be neither saturable nor dependent on cell type (49). Both passive transfer through the lipid bilayer of the plasma membrane as well as the formation of inverted micelles (45) have been postulated as possible translocation mechanisms, whereby the CPPs first bind to the lipid bilayer through electrostatic interaction (50). However, possible electrostatic interaction with other cell surface components cannot be ruled out $(27,51)$. If the postulated mechanisms seem to explain some aspects of CPP translocation and still appear to hold for peptides exhibiting lipid-binding capacity, it would seem unlikely that these mechanisms apply to highly hydrophilic CPPs (52). Moreover, there is no indication of increased membrane permeability in the presence of hydrophilic peptides. In fact, later studies have shown that CPP translocation is mostly a temperature-dependent process (53) and have established the possible role of endocytosis in the internalization of CPPs $(52,54,55)$. Given this newly found pathway, the question as to whether CPPs use receptor- or adsorptive-mediated endocytosis is raised. Structure-activity studies have shown that retro-, enantio- and/or retro-enantio analogues of CPPs retained the internalization properties of their parent peptides $(34,45,53,56)$, indicating that internalization does not depend on their specific primary sequences. This implies non-dependent stereospecific receptor recognition. CPPs have an obvious common feature in their cationic nature. Several studies have highlighted the crucial role of basic residues in the translocating ability of CPPs $(48,51,56)$. Of relevance to this is experimental evidence that HSPGs and/or other negatively charged cell surface components would take part in this function $(13,46,54,57)$. Where does this lead if not to adsorptive-mediated endocytosis?

\section{Selected CPPS}

Tat-Derived Peptides. The Tat protein is an 86 amino acid transcription factor involved in the replication cycle of HIV-1 virus. It has been demonstrated to be rapidly taken up by cells and to concentrate in the nucleus. The functional domain responsible for cell and nucleus import is the basic region extending from residues 49 to 58 (58). Since its initial description, many truncated versions of Tat which derived from this basic region have been described and shown to penetrate different cell types (48). Structure-activity relationship studies of the fragment Tat(38-60) and further truncated forms of this sequence, revealed that the whole basic region of Tat was a prerequisite for cellular peptide uptake $(53,56)$. One of the shortest peptides, Tat(48-60), which contains a nuclear localization signal, was defined as the minimal translocating peptide. Analogues of the peptide corresponding to its retro-, enantio- or retro-enantio form penetrated cells as efficiently as the parent peptide $(53,56)$. However, deletion of one or two arginine residues in the peptide sequence resulted in a significant or dramatic reduction of the cell-penetrating ability, while the deletion of three non-basic residues within this sequence did not affect the translocation property.

It has been suggested that the full-length Tat protein follows an adsorptive-mediated endocytic mechanism when internalized (59). The same internalization mechanism was also proposed for the green fluorescent protein (GFP)-Tat protein conjugate (60). Tat conjugated to fluorescent probes (59) or cargo proteins (61) was seen to be confined within cytoplasmic vesicles corresponding either to endosomes or lysosomes. Internalization of Tat protein was inhibited by heparin, but not by chondroitin sulfates, suggesting the possible involvement of HSPGs in the uptake mechanism (62). An inhibition of uptake was also demonstrated with other polyanions, such as suramin and pentosan sulfate (63). Furthermore, it has been shown that internalization of GFP fused to Tat protein is caveolae-mediated $(55,64)$. It was also suggested that the uptake mechanism might involve an interaction of the Tat protein with the sugar moiety of cell surface glypicans. In addition to the full-length Tat protein, the Tat-derived peptide (48-60) also seems to follow an energy- and temperature-dependent endocytic mechanism for its cellular internalization (52). The Tat(48-60) uptake, as well as that of Tat(48-60)-peptide nucleic acid (PNA) conjugate, were shown to be time-, temperature- and concentrationdependent (52,65). After internalization, the peptide and conjugates have been shown to display a characteristic endosomal distribution resulting in colocalization with common endocytic markers. Moreover, the role played by cell surface HSPGs in the uptake of Tat(48-60) and Tat fusion proteins reinforced the possibility of an adsorptive endocytic process $(54,66)$. GFP fused to Tat $(48-58)$ showed the use of the same internalization mechanism as GFP fused to the full-length Tat protein, as seen above (55).

Syn-B Vectors. This peptide family is derived from the natural antimicrobial peptide protegrin 1 (PG-1) originally isolated from porcine leukocytes. PG-1 is an 18 amino acid- 
long peptide with an antiparallel beta-sheet structure stabilized by two disulfide bridges (46). It interacts with, and forms pores in the lipid matrix of bacterial membranes (67). Various linear analogues of PG-1 that lack cysteine residues have been designed, which are devoid of the membrane-disrupting activity of PG-1. These linear peptides known as the Syn-B vectors, are able to interact with the cell surface and efficiently cross the plasma membrane $(27,68)$. Further optimizations have led to the development of shorter peptides (less than ten amino acids) that have improved translocation properties. As for the Tat-derived peptides, internalization of the Syn-B does not depend on a stereospecific receptor $(34,46)$. Syn-B peptides have been associated with adsorptive-mediated endocytosis $(34,46)$. Indeed, their transport into cells was demonstrated to be both energy-dependent and saturable, and inhibited in a competitive manner by polycationic molecules, such as poly-Llysine and protamine. Moreover, the $K_{\mathrm{D}}$ values measured for the Syn-B transport reside in the micromolar range, and compare well with the values observed for molecules described as being taken up by adsorptive-mediated endocytosis. Similar characteristics of transport were demonstrated for the cell uptake of Syn-B vectors conjugated to a fluorophore (27) or various drugs $(34,69,70)$.

Other Cell-Penetrating Peptides. The highly hydrophilic and cationic nature of poly-arginine (Arg) peptides makes endocytosis a likely pathway for their internalization. Indeed, the cellular uptake of (Arg) 9 and its PNA conjugate was seen to follow an energy-dependent endocytic pathway, with characteristics similar to those demonstrated for Tat(48-60) and its PNA conjugate (52). The use of a similar internalization pathway was also demonstrated for polyarginine (Arg)8 and poly-lysine (Lys)8 fused to the GFP (71).

Many other peptides have been reported to have cellpenetrating properties, some examples of which are given in Table III. Several reviews have taken the time to cover these peptides and their respective internalization mechanisms in greater detail (46,72,73). Adsorptive-mediated endocytosis was suggested for penetratin (residue sequence 43-58) $(27,51)$, biotinylated penetratin(43-58) bound to avidin or streptavidin (54), and for penetratin (residue sequence 42-58) conjugated to PNA (65), as well as for transportan conjugated to gold particles (74). However, other hypotheses have also been proposed to explain the transport mechanism. In fact, studies dealing with the kinetics of uptake show that the delivery process of these peptides may use two mechanisms simultaneously: a slow endocytic process and a rapid cellular penetration by passive diffusion across the lipid bilayer $(74,75)$. Formation of inverted micelles was also a proposed mechanism for the uptake of penetratin (45).

\section{In vitro Delivery to Cells and in vivo Delivery to Brain Tissue}

Examples of cargo delivery using CPPs are given in Table IV. Some general comments need to be made before going further. Although CPP vector-mediated strategies have proven their efficiency in carrying a variety of molecules into cells, evidence demonstrating the capacity of CPPs and CPPcargo constructs to permeate complex physiological barriers,

Table IV. Examples of Cargos Delivered by Selected Cell-Penetrating Peptides

\begin{tabular}{|c|c|c|c|c|}
\hline CPPs & Cargos & In vivo brain delivery & $\begin{array}{l}\text { In vitro cell } \\
\text { delivery }\end{array}$ & Refs. \\
\hline \multirow[t]{5}{*}{ L-Penetratin } & Antisense oligonucleotides & & $\swarrow$ & $(119,120)$ \\
\hline & GFP & & $\swarrow$ & $(121)$ \\
\hline & LFG & & $\swarrow$ & $(122)$ \\
\hline & p21(WAF1) & & $\swarrow$ & (123) \\
\hline & PNA & & $\mathscr{\swarrow}$ & (124) \\
\hline D-Penetratin & Doxorubicin & $\mathscr{\swarrow}$ & & $(34,81)$ \\
\hline \multirow{11}{*}{ Tat protein and Tat-derived peptides } & Antisense oligonucleotides & & $\prec$ & $(120)$ \\
\hline & Bcl-xL fusion protein & $\swarrow$ & & $(78,79)$ \\
\hline & Beta-galactosidase & $\mathscr{}$ & & $(77)$ \\
\hline & Beta-galactosidase & $x$ & $\swarrow$ & $(61)$ \\
\hline & Caspase-3 & & $\mathscr{\swarrow}$ & (125) \\
\hline & Domain III of Pseudomonas exotoxin A & & $\swarrow$ & $(61)$ \\
\hline & Fab antibody fragment & & $\prec$ & $(126)$ \\
\hline & GFP & & $\prec$ & (127) \\
\hline & Horseradish peroxidase & & $\swarrow$ & $(61)$ \\
\hline & RNase A & & $\prec$ & $(61)$ \\
\hline & p16INK4a & & $\prec$ & $(128)$ \\
\hline \multirow[t]{4}{*}{ Syn-B vectors } & Benzyl-penicillin & $\swarrow$ & & $(70)$ \\
\hline & Dalargin & $\swarrow$ & & (69) \\
\hline & Doxorubicin & $\swarrow$ & & (34) \\
\hline & Morphine-6-beta-d-glucuronide & $\prec$ & & (76) \\
\hline FBP & Oligonucleotides & & $\prec$ & (129) \\
\hline Homoarginines & PNA & & $\prec$ & $(52)$ \\
\hline
\end{tabular}

Brain or cell delivery, $\boldsymbol{x}$ no brain delivery, GFP green fluorescent protein, $L F G$ peptide motif serving as a docking site for cyclin/cyclindependent-kinase (cyclin-Cdk) complexes, p21(WAF1) cyclin inhibitor, PNA peptide nucleic acid; $B c l-x L$ death-suppressing molecule of the Bcl-2 family, p16INK $4 a$ inhibitor of cyclinD:Cdk4/6. 
such as the BBB, is still rare. Secondly, the therapeutic value of the CPP approach needs further documentation. Indeed, many cargo models used to demonstrate the ability of CPPs to efficiently translocate small or large molecules into cellsfor example fluorescent probes or the GFP or beta-galactosidase tags-have no therapeutic value whatsoever. However, there are several examples where CPPs have been used successfully to deliver therapeutic molecules through the BBB and into the brain, but as it stands today, most examples are limited to low molecular weight drugs and small peptide drugs $(34,69,70,76)$.

The first benchmark study of the ability of CPPs to deliver proteins across the BBB is probably that of Schwarze and Coll. (77) (Table IV). In this study, the authors examined the biodistribution of the Tat-derived peptide (47-57) fused to beta-galactosidase after intraperitoneal injection in mice. A strong beta-galactosidase activity was found in practically all tissues including the brain, demonstrating that the fusion protein had not only passed into many other tissues, but it had also crossed the BBB. Subsequently, various authors have used the Tat-based delivery approach for the transport of the Bcl-xL protein, a well-characterized death-suppressing molecule. Intraperitoneal injection of Bcl-xL fused to Tat into a murine stroke model has been shown to decrease cerebral infraction and attenuate ischemia-induced caspase-3 activation in ischemic neurons (78). Another study confirmed the neuroprotective effect of $\mathrm{Bcl}-\mathrm{xL}$ fused to Tat following intravenous injection in animal models of ischemic brain injury (79). However, there is other evidence showing that well-differentiated epithelial cells were essentially non-permeable to Tat(47-57) under physiological conditions (80). Furthermore, Tat peptides (1-72) or (37-72) conjugated to beta-galactosidase showed no penetration into the brain following intravenous injection, while a high tissue-associated activity was found in many other organs (61). Therefore, it is necessary to reconsider the general belief that CPP-mediated delivery may be technologically superior to commonly used delivery agents because of the practically unlimited systemic access of CPPs and potential for systemic drug delivery across cellular barriers.

Nevertheless, Syn-B vectors apparently enhance the delivery of different types of molecules across the BBB in vivo (Table IV). For example, the anticancer agent, doxorubicin, does not cross the BBB due to the presence of the Pglycoprotein (P-gp). Syn-B's efficiency in enhancing the brain uptake of doxorubicin has been demonstrated using in situ cerebral perfusion in rats and mice (34). Not only was the BBB integrity left uncompromised, but the Syn-B vectorized doxorubicin bypasses the P-gp (81). In comparison, there was a much smaller increase of BBB permeability to doxorubicin conjugated to D-penetratin; this permeability was possibly caused by the opening of the tight junctions. The ability of Syn-B vectors to enhance the brain uptake of doxorubicin was further assessed after intravenous injection of vectorized doxorubicin in mice (34). Significantly higher levels of the vectorized drug were measured in the brain, as compared to unmodified doxorubicin. Since these first promising studies, conjugating other pharmaceuticals to Syn-B vectors, such as benzyl penicillin (70), dalargin (69) and morphine-6-glucuronide (76), has shown to improve the uptake of these small cargos.

\section{Limitations and Pitfalls}

The ability of CPPs to penetrate many cell types in vitro, as well as in vivo greatly restricts their application as pharmaceutical tools. This is why targeted CPP delivery strategies need to be developed. Such strategies may exploit specific cell features, such as extracellular receptors or enzymes (82), or use small or large cell-binding ligands (e.g. vitamins, growth factors or antibodies) which, when incorporated into CPPs, may render these cationic peptides capable of distinguishing between non-target and target cells (83). Other problems are related to the stability of CPPs, and their toxicity and immunogenicity.

Stability. The stability of peptide vectors is an important factor regarding their use for in vivo delivery. The vector must not be metabolically cleaved until it delivers its cargo to the appropriate target. Only a few studies have investigated the cellular metabolism of CPPs. One of them examined and compared the stability of transportan, a transportan analogue, and penetratin (43-58) (84). The metabolic stability of the two former peptides was shown to be superior to that of penetratin. Another study showed the greater stability of Tat(47-57) also compared to penetratin (72). Stabilization of the peptide vectors may be achieved by using the D-form of the peptide, instead of the naturally occurring L-amino acids (85). The Dform is less sensitive to degradation by proteases and remains intact for a longer time than the L-form when injected in vivo. Vector stability may also be enhanced by using peptide mimics such as beta-peptides (86) or peptoides (56). On the one hand, the vector must be protected from degradation until it reaches the target; on the other hand, its subsequent degradation or removal is a prerequisite for the release of the transported cargo, leaving it free and able to exert its activity. However, premature cleavage of the CPP-cargo constructs may result in acute or chronic toxicity when used for therapeutic purposes.

Toxicity and Immunogenicity. Both toxicity and immunogenicity are other problems with CPPs. Various CPPs have been shown to exert a toxic action on cultured cells. The fulllength Tat protein and the Tat-derived peptides produced toxic effects on rat neuronal cultures, the importance of which was seen to depend on the length of the peptide (72). Thus, the full-length Tat protein produced lower levels of neurotoxicity than the shorter peptides Tat(31-71) and Tat(31-61) in that order. Both the cysteine-rich domain extending from residues 32 to 47 and the basic domain (positions 48-57) seem to be essential for neurotoxicity. Both regions were also demonstrated to induce endothelial cell apoptosis (87) and exert toxicity on HeLa cells (48). However, peptides containing only the basic region Tat(48-57) did not induce significant toxicity on cells, even when used at concentrations up to $100 \mu \mathrm{M}(48,87)$. In comparison, penetratin(43-58) used at concentrations in the range of $40-100 \mu \mathrm{M}$ produced cytotoxic effects $(27,72)$. Homoarginine peptides have been shown to alter the integrity of epithelial cell barriers in vitro (88), and to induce inflammation in rat lungs after intraperitoneal injection or intratracheal administration (89). The high adsorptive capacity of these cationic peptides to negatively charged surfaces in the pulmonary epithelium have been suggested to cause death after intratracheal administration. 
The immunogenicity of CPPs is poorly documented. Nevertheless it has to be stressed that most CPPs are derived from non-human proteins and, in the case of administration to humans, these peptides have the potential to induce an immune response. This risk may be considerably increased when these small carriers are conjugated to macromolecules.

\section{CONCLUSION}

Many leading protein drug treatments for brain diseases have been identified, and these may yield more favorable therapeutic indices than small molecule therapeutics. However, proteins do not cross the $\mathrm{BBB}$ and have little chance of being successful as brain drugs. The protein drug candidates need to be modified to overcome this transport obstacle. This may be done by the direct conversion of the protein carboxyl groups into extended primary amino groups (i.e. the cationization approach), or by the attachment of a cationic import peptide to the protein by chemical conjugation or genetic fusion (i.e. the CPP approach), in order to trigger transport across the $\mathrm{BBB}$ via an adsorptivemediated process (AMT). Cationization or the use of CPPs endows proteins with the ability to rapidly adsorb to negatively charged cell membranes and thus to penetrate a variety of different cells. These properties can interfere with specific brain targeting. On the other hand, the particularly high density of the capillary network of the brain may result in a high concentration of negative charges at the BBB. This concentration would create an environment selective for positively charged substances, and make AMT-based delivery strategies feasible, leading to the development of protein-based neurotherapeutics. Although the ability of cationization and CPPs to enhance the transport of proteins across cell membranes and the BBB is now well documented, the detailed mechanism by which molecules can bind to and cross the BBB via AMT remains unclear. What is known is that these molecules are internalized at the luminal side of the cerebral ECs, into membrane-bound vesicles after binding to various, not yet clearly identified, cell surface components bearing anionic sites. These molecules can then transcytose directly to the opposite side of the cell, or traffic inside the ECs in different ways, either accumulating in lysosomal compartments for degradation or eventually crossing the cell.

In view of these drawbacks, it is necessary to improve the brain targeting and clinical utility of protein drug delivery via AMT. One step would be to examine and identify the anionic components involved in the binding of cationized and CPP-vectorized proteins at the luminal membrane of the cerebral ECs. In addition, a better knowledge of the endocytic mechanisms involved in AMT would be helpful in avoiding lysosomal degradation in the ECs and in achieving transport of intact molecules to the underlying brain tissue. Glycomic and proteomic research would be useful in this area. Once the anionic sites have been identified and their binding properties determined, designing appropriate amino acid sequences of cationic vectors for the AMT process might be feasible. Additional factors like molecular weight as well as the cationic charge density also have to be considered when tailoring peptide vectors to increase AMT efficiency. Improving the brain selectivity of cationization- and CPP-based protein drug delivery strategies should also help decrease the dose necessary to obtain therapeutic efficacy, and this would, in turn, reduce the risks of toxicity and immunogenicity. Furthermore, it is clear that research focusing on the pharmacokinetic properties of cationized proteins and cationic import vectors cannot be neglected. Experimental evidence shows that brain-specific delivery of these molecules is often hampered by interactions with circulating proteins (e.g. serum albumin and alpha-1-acid glycoprotein) as well as with blood cell membranes, when these molecules are administered intravenously. This can lead to a decrease of the amount of the protein drug available for transfer into the brain. To improve drug delivery via AMT for the treatment of neurological diseases, we must reformulate the protein drug candidate or use galenic strategies to avoid undesirable interactions, and to protect the cationic proteins/ vectors from enzymatic degradation. In order to limit the effects of first pass blood flow, chemical techniques such as the PEGylation of the target macromolecule could be more widely used. Indeed, decorating the cationic proteins with PEG molecules masks the positive charges which, in turn, helps to limit interactions with peripheral tissues, prolongs circulatory time and reduces immunogenicity. In addition, new delivery systems should be developed or existing systems used more effectively. Coupling to cationic polymers, using liposomes, or developing new devices from nanovector technology may lead to high cerebral transfer of the target molecule and low toxicity. Future research should also focus on the routes of administration of protein drugs. Ideally, routes no more invasive than an intravenous or subcutaneous injection should be used in AMT-based brain drug delivery strategies. Unfortunately, some routes of delivery of cationized proteins, intravenous and intrapulmonary, result in severe adverse effects. Strategies as diverse as aerosolization of the target molecule-which distributes substances over a wider absorption surface than intravenous injection-new formulations or transient immune suppression should be re-examined in the context of increased efficiency of brain delivery and decreased immune response. Finally, combination strategies may also be used to increase the delivery of therapeutic molecules across the BBB. For example, it would be possible to associate the delivery strategy with another strategy for opening tight junctions reversibly (8) or for disrupting the polarization of phospholipids across cell membranes (90). Based upon progress in these multiple directions, we can reasonably expect that AMT will become an efficient physiologicallybased process for the brain delivery of protein drugs with a low permeability across the BBB.

\section{REFERENCES}

1. U. Bickel, T. Yoshikawa, and W. M. Pardridge. Delivery of peptides and proteins through the blood-brain barrier. $A d v$. Drug Deliv. Rev. 46:247-279 (2001).

2. P. L. Tuma and A. L. Hubbard. Transcytosis: crossing cellular barriers. Physiol. Rev. 83:871-932 (2003).

3. D. J. Begley and M. W. Brightman. Structural and functional aspects of the blood-brain barrier. Prog. Drug. Res. 61:39-78 (2003). 
4. M. Simionescu and N. Simionescu. Endothelial transport of macromolecules: transcytosis and endocytosis. A look from cell biology. Cell. Biol. Rev. 25:1-78 (1991).

5. M. Simionescu, N. Ghinea, A. Fixman, M. Lasser, L. Kukes, N. Simionescu, and G. E. Palade. The cerebral microvasculature of the rat: structure and luminal surface properties during early development. J. Submicrosc. Cytol. Pathol. 20:243-261 (1988).

6. W. M. Pardridge. Vector-mediated drug delivery to the brain. Adv. Drug Deliv. Rev. 36:299-321 (1999).

7. J. Huwyler, D. Wu, and W. M. Pardridge. Brain drug delivery of small molecules using immunoliposomes. Proc. Natl. Acad. Sci. USA 93:14164-14169 (1996).

8. D. S. Cox, S. Raje, H. Gao, N. N. Salama, and N. D. Eddington. Enhanced permeability of molecular weight markers and poorly bioavailable compounds across $\mathrm{Caco}-2$ cell monolayers using the absorption enhancer, zonula occludens toxin. Pharm. Res. 19:1680-1688 (2002).

9. U. Bickel. Antibody delivery through the blood-brain barrier. Adv. Dug. Deliv. Rev. 15:53-72 (1995).

10. J. F. Poduslo and G. L. Curran. Polyamine modification increases the permeability of proteins at the blood-nerve and blood-brain barriers. J. Neurochem. 66:1599-1609 (1996).

11. A. K. Kumagai, J. B. Eisenberg, and W. M. Pardridge. Absorptive-mediated endocytosis of cationized albumin and a beta-endorphin-cationized albumin chimeric peptide by isolated brain capillaries. Model system of blood-brain barrier transport. J. Biol. Chem. 262:15214-15219 (1987).

12. A. W. Vorbrodt. Ultracytochemical characterization of anionic sites in the wall of brain capillaries. J. Neurocytol. 18:359-368 (1989).

13. M. Belting. Heparan sulfate proteoglycan as a plasma membrane carrier. Trends. Biochem. Sci. 28:145-151 (2003).

14. B. L. Coomber and P. A. Stuart. Three-dimensional reconstruction of vesicles in endothelium of blood-brain barrier versus highly permeable microvessels. Anat. Rec. 215:256-261 (1986).

15. W. H. Oldendorf, M. E. Cornford, and W. J. Brown. The large apparent work capability of the blood-brain barrier: a study of the mitochondrial content of capillary endothelial cells in brain and other tissues of the rat. Ann. Neurol. 1:409-417 (1977).

16. W. Almers. Exocytosis. Annu. Rev. Physiol. 52:607-624 (1990).

17. W. M. Pardridge, J. Yang, and J. Eisenberg. Blood-brain barrier protein phosphorylation and dephosphorylation. J. Neurochem. 45:1141-1147 (1985).

18. R. D. Broadwell. Transcytosis of macromolecules through the blood-brain barrier: a cell biological perspective and critical appraisal. Acta. Neuropathol. 79:117-128 (1989).

19. J. E. Schnitzer. Caveolae: from basic trafficking mechanisms to targeting transcytosis for tissue-specific drug and gene delivery in vivo. Adv. Drug Deliv. Rev. 49:265-280 (2001).

20. S. A. Mousavi, L. Malerød, and R. Kjeken. Clathrin-dependent endocytosis. Biochem. J. 377:1-16 (2004).

21. M. T. Vu Hai, P. Lescop, H. Loosfelt, and N. Ghinea. Receptormediated transcytosis of follicle-stimulating hormone through the rat testicular microvasculature. Biol. Cell. 9:133-144 (2004).

22. G. R. Hayes, C. A. Enns, and J. J. Lucas. Identification of the O-linked glycosylation site of the human transferrin receptor. Glycobiology 2:355-359 (1992).

23. J. Girod, L. Fenart, A. Régina, M. P. Dehouck, G. Hong, J. M. Scherrmann, R. Cecchelli, and F. Roux. Transport of cationized anti-tetanus Fab'2 fragments across an in vitro blood-brain barrier model: involvement of the transcytosis pathway. $J$. Neurochem. 73:2002-2008 (1999).

24. G. Hong, O. Chappey, E. Niel, and J. M. Scherrmann. Enhanced cellular uptake and transport of polyclonal immunoglobulin $\mathrm{G}$ and Fab after their cationization. J. Drug Target. 8:67-77 (2000).

25. F. Welfringer, P. d'Athis, J. M. Scherrmann, and F. Hervé. Development and validation of an antigen-binding capture ELISA for native and putrescine-modified anti-tetanus F(ab')2 fragments for the assessment of the cellular uptake and plasma kinetics of the antibodies. J. Immunol. Methods. 307:82-95 (2005).

26. F. Hervé, N. Ghinea, P. d'Athis, P. A. Carrupt, and J. M. Scherrmann. Covalent modifications of anti-tetanus F(ab')2 fragments with natural and synthetic polyamines and their effects on the antibody endocytosis in cultured HL60 cells. Bionconjug Chem (2008) doi:10.1021/bc800045x.

27. G. Drin, S. Cottin, E. Blanc, A. R. Rees, and J. Temsamani. Studies on the internalization mechanism of cationic cellpenetrating peptides. J. Biol. Chem. 278:31192-31201 (2003).

28. D. Soulet, B. Gagnon, S. Rivest, M. Audette, and R. Poulin. A fluorescent probe of polyamine transport accumulates into intracellular acidic vesicles via a two-step mechanism. J. Biol. Chem. 279:49355-49366 (2004).

29. M. Belting, K. Mani, M. Jönsson, F. Cheng, S. Sandgren, S. Jonsson, K. Ding, J. G. Delcros, and L. A. Fransson. Glypican-1 is a vehicle for polyamine uptake in mammalian cells. A pivotal role for nitrosothiol-derived nitric oxide. J. Biol. Chem. 278:47181-47189 (2003).

30. R. D. Egleton and T. P. Davis. Bioavailability and transport of peptides and peptide drugs into the brain. Peptides 18:14311439 (1997).

31. A. E. Pegg. Recent advances in the biochemistry of polyamines in eukaryotes. Biochem. J. 234:249-262 (1986).

32. M. M. Reinholz, J. J. Haggard, G. L. Curran, and J. F. Poduslo. Plasma pharmacokinetics, nervous system biodistribution and biostability, and spinal cord permeability at the blood-brain barrier of putrescine-modified catalase in the adult rat. Exp. Neurol. 159:191-203 (1999).

33. T. M. Wengenack, G. L. Curran, and J. F. Poduslo. Postischemic, systemic administration of polyamine-modified superoxide dismutase reduces hippocampal CA1 neurodegeneration in rat global cerebral ischemia. Brain Res. 754:46-54 (1997).

34. C. Rousselle, M. Smirnova, P. Clair, J. M. Lefauconnier, A. Chavanieu, B. Calas, J. M. Scherrmann, and J. Temsamani. Enhanced delivery of doxorubicin into the brain via a peptidevector-mediated strategy: saturation kinetics and specificity. $J$. Pharmacol. Exp. Ther. 296:124-131 (2001).

35. L. J. Nell and J. W. Thomas. Frequency and specificity of protamine antibodies in diabetic and control subjects. Diabetes 37:172-176 (1988).

36. A. Muckerheide, R. J. Apple, A. J. Pesce, and J. G. Michael. Cationization of protein antigens. I. Alteration of immunogenic properties. J. Immunol. 138:833-837 (1987).

37. J. F. Poduslo, M. Ramakrishnan, S. S. Holasek, M. RamirezAlvarado, K. K. Kandimalla, E. J. Gilles, G. L. Curran, and T. M. Wengenack. In vivo targeting of antibody fragments to the nervous system for Alzheimer's disease immunotherapy and molecular imaging of amyloid plaques. J. Neurochem. 102:420 433 (2007).

38. M. M. Reinholz, C. M. Merkle, and J. F. Poduslo. Therapeutic benefits of putrescine-modified catalase in a transgenic mouse model of familial amyotrophic lateral sclerosis. Exp. Neurol. 159:204-216 (1999).

39. J. F. Poduslo, S. L. Whelan, G. L. Curran, and T. M. Wengenack. Therapeutic benefit of polyamine-modified catalase as a scavenger of hydrogen peroxide and nitric oxide in familial amyotrophic lateral sclerosis transgenics. Ann. Neurol. 48:943-947 (2000).

40. J. Futami, M. Kitazoe, H. Murata, and H. Yamada. Exploiting protein cationization techniques in future drug development. Expert. Opin. Drug Discov. 2:261-269 (2007).

41. P. R. Lockman and D. D. Allen. The transport of choline. Drug Dev. Ind. Pharm. 28:749-771 (2002).

42. H. Koepsell. Polyspecific organic cation transporters: their functions and interactions with drugs. Trends. Pharmacol. Sci. 25:375-381 (2004).

43. L. Fenart, A. Casanova, B. Dehouck, C. Duhem, S. Slupek, R. Cecchelli, and D. Betbeder. Evaluation of effect of charge and lipid coating on ability of 60-nm nanoparticles to cross an in vitro model of the blood-brain barrier. J. Pharmacol. Exp. Ther. 291:1017-1022 (1999).

44. M. Voiena and M. Simionescu. Designing of "intelligent" liposomes for efficient delivery of drugs. J. Cell. Mol. Med. 4:465-474 (2002).

45. M. Lindgren, M. Hällbrink, A. Prochiantz, and U. Langel. Cellpenetrating peptides. Trends. Pharmacol. Sci. 21:99-103 (2000).

46. G. Drin, C. Rousselle, J. M. Scherrmann, A. R. Rees, and J. Temsamani. Peptide delivery to the brain via adsorptive- 
mediated endocytosis: advances with SynB vectors. AAPS PharmSci. 4:E26, 2002 (2002).

47. R. Fischer, T. Waizenegger, K. Köhler, and R. Brock. A quantitative validation of fluorophore-labelled cell-permeable peptide conjugates: fluorophore and cargo dependence of import. Biochim. Biophys. Acta. 1564:365-374 (2002).

48. E. Vivès, P. Brodin, and B. Lebleu. A truncated HIV-1 Tat protein basic domain rapidly translocates through the plasma membrane and accumulates in the cell nucleus. J. Biol. Chem. 272:16010-16017 (1997).

49. M. A. Bogoyevitch, T. S. Kendrick, D. C. Ng, and R. K. Barr. Taking the cell by stealth or storm? Protein transduction domains (PTDs) as versatile vectors for delivery. DNA. Cell. Biol. 21:879-894 (2002).

50. P. E. Thorén, D. Persson, M. Karlsson, and B. Nordén. The antennapedia peptide penetratin translocates across lipid bilayers - the first direct observation. FEBS. Lett. 482:265-268 (2000).

51. G. Drin, M. Mazel, P. Clair, D. Mathieu, M. Kaczorek, and J. Temsamani. Physico-chemical requirements for cellular uptake of pAntp peptide. Role of lipid-binding affinity. Eur. J. Biochem. 268:1304-1314 (2001).

52. J. P. Richard, K. Melikov, E. Vives, C. Ramos, B. Verbeure, M. J. Gait, L. V. Chernomordik, and B. Lebleu. Cell-penetrating peptides. A reevaluation of the mechanism of cellular uptake. $J$. Biol. Chem. 278:585-590 (2003).

53. E. Vivès, J. P. Richard, C. Rispal, and B. Lebleu. TAT peptide internalization: seeking the mechanism of entry. Curr. Protein. Pept. Sci. 4:125-132 (2003).

54. S. Console, C. Marty, C. Garcia-Echeverria, R. Schwendener, and K. Ballmer-Hofer. Antennapedia and HIV transactivator of transcription (TAT) "protein transduction domains" promote endocytosis of high molecular weight cargo upon binding to cell surface glycosaminoglycans. J. Biol. Chem. 278:35109-35114 (2003).

55. A. Fittipaldi, A. Ferrari, M. Zoppé, C. Arcangeli, V. Pellegrini, F. Beltram, and M. Giacca. Cell membrane lipid rafts mediate caveolar endocytosis of HIV-1 Tat fusion proteins. J. Biol. Chem. 278:34141-34149 (2003).

56. P. A. Wender, D. J. Mitchell, K. Pattabiraman, E. T. Pelkey, L. Steinman, and J. B. Rothbard. The design, synthesis, and evaluation of molecules that enable or enhance cellular uptake: peptoid molecular transporters. Proc. Natl. Acad. Sci. U. S. A. 97:13003-13008 (2000).

57. T. Suzuki, S. Futaki, M. Niwa, S. Tanaka, K. Ueda, and Y. Sugiura. Possible existence of common internalization mechanisms among arginine-rich peptides. J. Biol. Chem. 277:24372443 (2002).

58. B. E. Vogel, S. J. Lee, A. Hildebrand, W. Craig, M. D. Pierschbacher, F. Wong-Staal, and E. Ruoslahti. A novel integrin specificity exemplified by binding of the alpha $\mathrm{v}$ beta 5 integrin to the basic domain of the HIV Tat protein and vitronectin. J. Cell. Biol. 121:461-468 (1993).

59. D. A. Mann and A. D. Frankel. Endocytosis and targeting of exogenous HIV-1 Tat protein. EMBO. J. 10:1733-1739 (1991).

60. M. Silhol, M. Tyagi, M. Giacca, B. Lebleu, and E. Vivès. Different mechanisms for cellular internalization of the HIV-1 Tat-derived cell penetrating peptide and recombinant proteins fused to Tat. Eur. J. Biochem. 269:94-501 (2002).

61. S. Fawell, J. Seery, Y. Daikh, C. Moore, L. L. Chen, B. Pepinsky, and J. Barsoum. Tat-mediated delivery of heterologous proteins into cells. Proc. Natl. Acad. Sci. U. S. A. 91:664668 (1994).

62. M. Tyagi, M. Rusnati, M. Presta, and M. Giacca. Internalization of HIV-1 tat protein requires cell surface heparan sulfate proteoglycans. J. Biol. Chem. 276:3254-3261 (2001).

63. M. Rusnati, C. Urbinati, A. Caputo, L. Possati, H. Lortat-Jacob, M. Giacca, D. Ribatti, and M. Presta. Pentosan polysulfate as an inhibitor of extracellular HIV-1 Tat. J. Biol. Chem. 276:22420-22425 (2001).

64. A. Ferrari, V. Pellegrini, C. Arcangeli, A. Fittipaldi, M. Giacca, and F. Beltram. Caveolae-mediated internalization of extracellular HIV-1 tat fusion proteins visualized in real time. Mol. Ther. 8:284-294 (2003).
65. U. Koppelhus, S. K. Awasthi, V. Zachar, H. U. Holst, P. Ebbesen, and P. E. Nielsen. Cell-dependent differential cellular uptake of PNA, peptides, and PNA-peptide conjugates. Antisense. Nucleic. Acid Drug Dev. 12:51-63 (2002).

66. S. Sandgren, F. Cheng, and M. Belting. Nuclear targeting of macromolecular polyanions by an HIV-Tat derived peptide. Role for cell-surface proteoglycans. J. Biol. Chem. 277:3887738883 (2002).

67. Y. Sokolov, T. Mirzabekov, D. W. Martin, R. I. Lehrer, and B. L. Kagan. Membrane channel formation by antimicrobial protegrins. Biochim. Biophys. Acta. 1420:23-29 (1999).

68. G. Drin and J. Temsamani. Translocation of protegrin I through phospholipid membranes: role of peptide folding. Biochim. Biophys. Acta. 1559:160-170 (2002).

69. C. Rousselle, P. Clair, M. Smirnova, Y. Kolesnikov, G. W. Pasternak, S. Gac-Breton, A. R. Rees, J. M. Scherrmann, and J. Temsamani. Improved brain uptake and pharmacological activity of dalargin using a peptide-vector-mediated strategy. $J$. Pharmacol. Exp. Ther. 306:371-376 (2003).

70. C. Rousselle, P. Clair, J. Temsamani, and J. M. Scherrmann. Improved brain delivery of benzyl penicillin with a peptidevector-mediated strategy. J. Drug Target 10:309-315 (2002).

71. M. Lundberg, S. Wikström, and M. Johansson. Cell surface adherence and endocytosis of protein transduction domains. Mol. Ther. 8:143-150 (2003).

72. R. Tréhin and H. P. Merkle. Chances and pitfalls of cell penetrating peptides for cellular drug delivery. Eur. J. Pharm. Biopharm. 58:209-223 (2004).

73. J. Temsamani and P. Vidal. The use of cell-penetrating peptides for drug delivery. Drug. Discov. Today 9:1012-1019 (2004).

74. M. Pooga, C. Kut, M. Kihlmark, M. Hällbrink, S. Fernaeus, R. Raid, T. Land, E. Hallberg, T. Bartfai, and U. Langel. Cellular translocation of proteins by transportan. FASEB. J. 15:14511453 (2001).

75. M. Hällbrink, A. Florén, A. Elmquist, M. Pooga, T. Bartfai, and U. Langel. Cargo delivery kinetics of cell-penetrating peptides. Biochim. Biophys. Acta. 1515:101-109 (2001).

76. F. Bourasset, S. Cisternino, J. Temsamani, and J. M. Scherrmann. Evidence for an active transport of morphine-6-beta- $d$ glucuronide but not P-glycoprotein-mediated at the blood-brain barrier. J. Neurochem. 86:1564-1567 (2003).

77. S. R. Schwarze, A. Ho, A. Vocero-Akbani, and S. F. Dowdy. In vivo protein transduction: delivery of a biologically active protein in the mouse. Science 285:1569-1572 (1999).

78. G. Cao, W. Pei, H. Ge, Q. Liang, Y. Luo, F. R. Sharp, A. Lu, R. Ran, S. H. Graham, and J. Chen. In vivo delivery of a Bcl-xL fusion protein containing the TAT protein transduction domain protects against ischemic brain injury and neuronal apoptosis. $J$. Neurosci. 22:5423-5431 (2002).

79. E. Kilic, G. P. Dietz, D. M. Hermann, and M. Bähr. Intravenous TAT-Bcl-Xl is protective after middle cerebral artery occlusion in mice. Ann. Neurol. 52:617-622 (2002).

80. S. Violini, V. Sharma, J. L. Prior, M. Dyszlewski, and D. Piwnica-Worms. Evidence for a plasma membrane-mediated permeability barrier to Tat basic domain in well-differentiated epithelial cells: lack of correlation with heparan sulfate. Biochemistry 41:12652-12661 (2002).

81. M. Mazel, P. Clair, C. Rousselle, P. Vidal, J. M. Scherrmann, D. Mathieu, and J. Temsamani. Doxorubicin-peptide conjugates overcome multidrug resistance. Anticancer Drugs 12:107-116 (2001)

82. T. Jiang, E. S. Olson, Q. T. Nguyen, M. Roy, P. A. Jennings, and R. Y. Tsien. Tumor imaging by means of proteolytic activation of cell-penetrating peptides. Proc. Natl. Acad. Sci. U. S. A. 101:17867-17872 (2004)

83. E. Wagner, C. Culmsee, and S. Boeckle. Targeting of polyplexes: toward synthetic virus vector systems. Adv. Genet. 53PA:333-354 (2005).

84. M. E. Lindgren, M. M. Hällbrink, A. M. Elmquist, and U. Langel. Passage of cell-penetrating peptides across a human epithelial cell layer in vitro. Biochem. J. 377:69-76 (2004).

85. J. Brugidou, C. Legrand, J. Méry, and A. Rabié. The retroinverso form of a homeobox-derived short peptide is rapidly internalised by cultured neurons: a new basis for an efficient 
intracellular delivery system. Biochem. Biophys. Res. Comm. 214:685-693 (1995).

86. M. Rueping, Y. Mahajan, M. Sauer, and D. Seebach. Cellular uptake studies with beta-peptides. Chembiochem 3:257-259 (2002).

87. H. Jia, M. Lohr, S. Jezequel, D. Davis, S. Shaikh, D. Selwood, and I. Zachary. Cysteine-rich and basic domain HIV-1 Tat peptides inhibit angiogenesis and induce endothelial cell apoptosis. Biochem. Biophys. Res. Comm. 283:469-479 (2001).

88. S. Shahana, C. Kampf, and G. M. Roomans. Effects of the cationic protein poly-L-arginine on airway epithelial cells in vitro. Mediators. Inflamm. 11:141-148 (2002).

89. A. Santana, S. Hyslop, E. Antunes, M. Mariano, Y. S. Bakhle, and G. Nuccide. Inflammatory responses induced by poly-Larginine in rat lungs in vivo. Agents Actions 39:104-110 (1993).

90. X. Huang, M. Bennett, and P. E. Thorpe. A monoclonal antibody that binds anionic phospholipids on tumor blood vessels enhances the antitumor effect of docetaxel on human breast tumors in mice. Cancer. Res. 65:4408-4416 (2005).

91. K. R. Smith and R. T. Borchardt. Permeability and mechanism of albumin, cationized albumin, and glycosylated albumin transcellular transport across monolayers of cultured bovine brain capillary endothelial cells. Pharm. Res. 6:466-473 (1989).

92. J. F. Poduslo, G. L. Curran, and C. T. Berg. Macromolecular permeability across the blood-nerve and blood-brain barriers. Proc. Natl. Acad. Sci. USA 91:5705-5709 (1994).

93. L. Descamps, M. P. Dehouck, G. Torpier, and R. Cecchelli. Receptor-mediated transcytosis of transferrin through bloodbrain barrier endothelial cells. Am. J. Physiol. 270:H1149H1158 (1996).

94. R. D. Broadwell, B. J. Baker-Cairns, P. M. Friden, C. Oliver, and J. C. Villegas. Transcytosis of protein through the mammalian cerebral epithelium and endothelium. III. Receptor-mediated transcytosis through the blood-brain barrier of blood-borne transferrin and antibody against the transferrin receptor. Exp. Neurol. 142:47-65 (1996).

95. B. Dehouck, L. Fenart, M. P. Dehouck, A. Pierce, G. Torpier, and R. Cecchelli. A new function for the LDL receptor: transcytosis of LDL across the blood-brain barrier. J. Cell. Biol. 138:877-889 (1997).

96. W. M. Pardridge, Y. S. Kang, J. L. Buciak, and J. Yang. Human insulin receptor monoclonal antibody undergoes high affinity binding to human brain capillaries in vitro and rapid transcytosis through the blood-brain barrier in vivo in the primate. Pharm. Res. 12:807-816 (1995).

97. R. R. Reinhardt and C. A. Bondy. Insulin-like growth factors cross the blood-brain barrier. Endocrinology 135:1753-1761 (1994).

98. P. L. Golden, T. J. Maccagnan, and W. M. Pardridge. Human blood-brain barrier leptin receptor. Binding and endocytosis in isolated human brain microvessels. J. Clin. Invest. 99:14-18 (1997).

99. J. F. Poduslo, G. L. Curran, B. Sanyal, and D. J. Selkoe. Receptor-mediated transport of human amyloid beta-protein 140 and 1-42 at the blood-brain barrier. Neurobiol. Dis. 6:190199 (1999).

100. W. M. Pardridge and R. J. Boado. Enhanced cellular uptake of biotinylated antisense oligonucleotides or peptide mediated by avidin, a cationic protein. FEBS. Lett. 288:30-32 (1991).

101. W. M. Pardridge, D. Triguero, and J. Buciak. Transport of histone through the blood-brain barrier. J. Pharmacol. Exp. Ther. 251:821-826 (1989).

102. W. M. Pardridge, J. L. Buciak, Y. S. Kang, and R. J. Boado. Protamine-mediated transport of albumin into brain and other organs of the rat. Binding and endocytosis of protaminealbumin complex by microvascular endothelium. J. Clin. Invest. 92:2224-2229 (1993).

103. J. C. Villegas and R. D. Broadwell. Transcytosis of protein through the mammalian cerebral epithelium and endothelium. II Adsorptive-transcytosis of WGA-HRP and the blood-brain and brain-blood barriers. J. Neurocytol. 22:67-80 (1993).

104. T. J. Raub, and K. L. Audus. Adsorptive endocytosis and membrane recycling by cultured primary bovine brain microvessel endothelial cell monolayers. J. Cell. Sci. 97:127-138 (1990).
105. I. Tamai, Y. Sai, H. Kobayashi, M. Kamata, T. Wakamiya, and A. Tsuji. Structure-internalization relationship for adsorptivemediated endocytosis of basic peptides at the blood-brain barrier. J. Pharmacol. Exp. Ther. 280:410-415 (1997).

106. T. Shimura, S. Tabata, T. Ohnishi, T. Terasaki, and A. Tsuji. Transport mechanism of a new behaviorally highly potent adrenocorticotropic hormone (ACTH) analog, ebitaride, through the blood-brain barrier. J. Pharmacol. Exp. Ther 258:459-465 (1991).

107. T. Terasaki, Y. Deguchi, H. Sato, K. Hirai, and A. Tsuji. In vivo transport of a dynorphin-like analgesic peptide, E-2078, through the blood-brain barrier: an application of brain microdialysis. Pharm. Res. 8:815-820 (1991).

108. K. K. Kandimalla, G. L. Curran, S. S. Holasek, E. J. Gilles, T. M. Wengenack, M. Ramirez-Alvarado, and J. F. Poduslo Physiological and biophysical factors that influence Alzheimer's disease amyloid plaque targeting of native and putrescine modified human amyloid beta40. J. Pharmacol. Exp. Ther. 318:17-25 (2006).

109. J. F. Poduslo, G. L. Curran, A. Kumar, B. Frangione, and C. Soto. Beta-sheet breaker peptide inhibitor of Alzheimer's amyloidogenesis with increased blood-brain barrier permeability and resistance to proteolytic degradation in plasma. $J$. Neurobiol. 39:371-382 (1999).

110. J. F. Poduslo, G. L. Curran, and J. S. Gill. Putrescine-modified nerve growth factor: bioactivity, plasma pharmacokinetics, blood-brain/nerve barrier permeability, and nervous system biodistribution. J. Neurochem. 71:1651-1660 (1998).

111. W. M. Pardridge, D. Triguero, and J. L. Buciak. Beta-endorphin chimeric peptide: transport through the blood-brain barrier in vivo and cleavage of disulfide linkage by brain. Endocrinology 126:977-984 (1990).

112. M. Thöle, S. Nobmanna, J. Huwyler, A. Bartmann, and G. Fricker. Uptake of cationized albumin coupled liposomes by cultured porcine brain microvessel endothelial cells and intact brain capillaries. J. Drug. Target. 10:337-344 (2002)

113. J. F. Poduslo and G. L. Curran. Amyloid beta peptide as a vaccine for Alzheimer's disease involves receptor-mediated transport at the blood-brain barrier. Neuroreport 12:3197-3200 (2001).

114. J. Oehlke, A. Scheller, B. Wiesner, E. Krause, M. Beyermann, E. Klauschenz, M. Melzig, and M. Bienert. Cellular uptake of an alpha-helical amphipathic model peptide with the potential to deliver polar compounds into the cell interior non-endocytically. Biochim. Biophys. Acta. 1414:127-139 (1998).

115. M. Pooga, M. Hällbrink, M. Zorko, and U. Langel. Cell penetration by transportan. FASEB. J. 12:67-77 (1998).

116. L. Chaloin, P. Vidal, A. Heitz, N. MauVan, J. Méry, G. Divita, and F. Heitz. Conformations of primary amphipathic carrier peptides in membrane mimicking environments. Biochemistry 36:11179-11187 (1997).

117. L. Chaloin, P. Vidal, P. Lory, J. Méry, N. Lautredou, G. Divita, and F. Heitz. Design of carrier peptide-oligonucleotide conjugates with rapid membrane translocation and nuclear localization properties. Biochem. Biophys. Res. Comm. 243:601-608 (1998).

118. D. J. Mitchell, D. T. Kim, L. Steinman, C. G. Fathman, and J. B. Rothbard. Polyarginine enters cells more efficiently than other polycationic homopolymers. J. Pept. Res. 56:318-325 (2000).

119. C. M. Troy, D. Derossi, A. Prochiantz, L. A. Greene, and M. L. Shelanski. Downregulation of $\mathrm{Cu} / \mathrm{Zn}$ superoxide dismutase leads to cell death via the nitric oxide-peroxynitrite pathway. J. Neurosci. 16:253-261 (1996).

120. A. Astriab-Fisher, D. S. Sergueev, M. Fisher, B. R. Shaw, and R. L. Juliano. Antisense inhibition of P-glycoprotein expression using peptide-oligonucleotide conjugates. Biochem. Pharmacol. 60:83-90 (2000).

121. K. Han, M. J. Jeon, K. A. Kim, J. Park, and S. Y. Choi. Efficient intracellular delivery of GFP by homeodomains of Drosophila fushi-tarazu and engrailed proteins. Mol. Cells 10:728-732 (2000).

122. Y. N. Chen, S. K. Sharma, T. M. Ramsey, L. Jiang, M. S. Martin, K. Baker, P. D. Adams, K. W. Bair, and W. G. Kaelin Jr. Selective killing of transformed cells by cyclin/cyclin-dependent kinase 2 antagonists. Proc. Natl. Acad. Sci. U. S. A. 96:4325-4329 (1999). 
123. M. Bonfanti, S. Taverna, M. Salmona, M. D'Incalci, and M. Broggini. p21WAF1-derived peptides linked to an internalization peptide inhibit human cancer cell growth. Cancer. Res. 57:1442-1446 (1997).

124. M. Pooga, U. Soomets, M. Hällbrink, A. Valkna, K. Saar, K. Rezaei, U. Kahl, J. X. Hao, X. J. Xu, Z. Wiesenfeld-Hallin, T. Hökfelt, T. Bartfai, and U. Langel. Cell penetrating PNA constructs regulate galanin receptor levels and modify pain transmission in vivo. Nat. Biotechnol. 16:857-861 (1998).

125. A. M. Vocero-Akbani, N. V. Heyden, N. A. Lissy, L. Ratner, and S. F. Dowdy. Killing HIV-infected cells by transduction with an HIV protease-activated caspase-3 protein. Nat. Med. 5:29-33 (1999).

126. D. C. Anderson, R. Manger, J. Schroeder, D. Woodle, M. Barry, A. C. Morgan, and A. R. Fritzberg. Enhanced in vitro tumor cell retention and internalization of antibody derivatized with synthetic peptides. Bioconjug. Chem. 4:1018 (1993)

127. N. J. Caron, Y. Torrente, G. Camirand, M. Bujold, P. Chapdelaine, K. Leriche, N. Bresolin, and J. P. Tremblay. Intracellular delivery of a Tat-eGFP fusion protein into muscle cells. Mol. Ther. 3:310-318 (2001).

128. D. R. Gius, S. A. Ezhevsky, M. Becker-Hapak, H. Nagahara, M. C. Wei, and S. F. Dowdy. Transduced p16INK4a peptides inhibit hypophosphorylation of the retinoblastoma protein and cell cycle progression prior to activation of Cdk2 complexes in late G1. Cancer. Res. 59:2577-2580 (1999).

129. M. C. Morris, P. Vidal, L. Chaloin, F. Heitz, and G. Divita. A new peptide vector for efficient delivery of oligonucleotides into mammalian cells. Nucleic. Acids. Res. 25:2730-2736 (1997). 